Article

\title{
Stimulation of Light-Emitting Diode Treatment on Defence System and Changes in Mesocarp Metabolites of Avocados Cultivars (Hass and Fuerte) during Simulated Market Shelf Conditions
}

\author{
Semakaleng Mpai and Dharini Sivakumar *(i) \\ Department of Crop Sciences, Phytochemical Food Network, Tshwane University of Technology, Pretoria 0001, \\ South Africa; semkalengmpai@gmail.com \\ * Correspondence: SivakumarD@tut.ac.za
}

Received: 19 August 2020; Accepted: 19 October 2020; Published: 27 October 2020

\begin{abstract}
The ability of light-emitting diode (LED) light treatment to reduce the anthracnose decay via its eliciting effects and thus induce resistance in the avocado (Persea americana), was investigated in this study to replace the current postharvest fungicide treatment. In experiment 1 , the effect of blue or red LED lights ( $6 \mathrm{~h}$ per day) on the incidence of anthracnose in artificially inoculated (Colletotrichum gloesposorioides) and naturally infected avocados (cv. Fuerte and Hass) at $12-14{ }^{\circ} \mathrm{C}$ (simulated market shelf) for 4, 8, 14, and 16 days was investigated. In experiment 2, the effect of blue or red LED lights on the induced defence mechanism, fruit metabolites, antioxidant activity, and percentage of fruit reaching ready-to-eat stage was determined. Exposure to red LED light significantly reduced the anthracnose decay incidence in naturally infected cv. Fuerte on day 12 and in cv. Hass on day 16 compared to the prochloraz fungicide treatment by upregulating the PAL genes and maintaining the epicatechin content. Blue LED light accelerated the ripening in both cultivars, probably due to reduced D-mannoheptulose content. Red LED light exposure for $6 \mathrm{~h}$ per day and 12 days storage showed potential to replace the prochloraz treatment with improved ascorbic acid content and antioxidant activity.
\end{abstract}

Keywords: Persea americana; phenolic compounds; ripening; postharvest decay; D-mannoheptulose; phenylalanine ammonia lyase

\section{Introduction}

Avocado (Persea americana) is a popular subtropical fruit amongst consumers for its health benefits. Consumption of half an avocado (68 g) reportedly provides dietary fibre $(4.6 \mathrm{~g})$, potassium (345 $\mathrm{mg})$, vitamin C $(6.0 \mathrm{mg})$, vitamin E $(1.3 \mathrm{mg})$, folate $(60 \mathrm{mg})$, choline $(10 \mathrm{mg})$, lutein/zeaxanthin (185 $\mu \mathrm{g})$, phytosterols (57 mg), and a high level of monounsaturated fatty acids (6.7 g) [1]. Among the avocado cultivars, consumers mainly prefer the dark-skinned cv. Hass because of its creamy and smooth texture and nutty taste, whilst the green-skinned cv. Fuerte is popular due to its good flavour and oily texture [2]. Consumer preference is high for "ready-to-eat stage" avocados [3], but due to postharvest decay anthracnose (Colletotrichum gloeosporioides Penz.), the quality of fruit can be negatively affected, and postharvest losses during marketing are high [4]. Avocado is a climacteric fruit, which reaches ready to ripe stage after harvest at the climacteric peak with ethylene emission, resulting in structural and biochemical changes and reduction of antifungal compounds to alleviate the dormancy of C. gloeosporioides, the latent pathogen [4]. The symptoms are expressed in the fruit at trigger-ripe stage, especially during marketing on the supermarket cold shelf at $12-14{ }^{\circ} \mathrm{C}$ [5]. 
In most avocado-exporting countries, Prochloraz, a chemically synthesised fungicide, is applied as a spray or dip in the packing line to provide residual protection against the anthracnose-causing organism during marketing [4]. However, Prochloraz has hazardous health effects, and the maximum residue limits (MRLs) for the South African avocado limits its access to the quality-stringent export markets [6]. Consequently, numerous alternative green technologies have actively undergone research during the past 5 years to replace the Prochloraz fungicide treatment [7].

The use of a light-emitting diode (LED), as a nonchemical treatment for maintaining quality attributes of horticultural produce, is becoming popular [8]. Light-emitting diode (LED) lights are becoming increasingly used in horticulture because of their energy efficiency, durability, longer lifetimes, low thermal energy, and cost effectiveness $[9,10]$. Due to the aforementioned desirable effects of LED lights, their use is highly recommended during storage (cold rooms) or transportation (refrigerated trucks) as an alternative green technology to minimise postharvest losses while maintaining product quality $[8,10]$. Moreover, the specific monochromatic spectrum of red LED lights was found to improve bioactive compounds, total phenols, ascorbic acid content, and antioxidant activity in yellow and green fresh-cut sweet peppers for 7 and 11 days, respectively [10]. Blue LED light ameliorated the accumulation of the aforementioned bioactive compounds in fresh-cut red sweet pepper up to 11 days at $7{ }^{\circ} \mathrm{C}$ and $85 \% \mathrm{RH}$, indicating different responses or interactions in the accumulation of bioactive compounds with regard to different genotypes and the type of LED light [10]. Additionally, blue LED light pretreatment delayed ripening and fruit softening and extended the shelf life of tomatoes (climacteric crop) [11]. Conversely, blue LED light treatment (emission peak of $465 \mathrm{~nm}$ and fluency of $8 \mu \mathrm{mol} \cdot \mathrm{m}^{-2} \cdot \mathrm{s}^{-1}$ ) accelerated ripening in bananas (climacteric fruit) and significantly reduced the blue mould (Penicillium italicum) infection in Satsuma Mandarin (citrus) fruit [12].

However, the influence of monochromatic LED light color and exposure time during storage on avocado fruit quality and postharvest decay (anthracnose) are unknown in the effort to replace the commercially used Prochloraz application. Therefore, the study comprises four objectives to evaluate the influence of red or blue LED light treatments and storage periods compared to the commercial control, i.e., Prochloraz treatment, on (i) anthracnose incidence, phenylalanine ammonia lyase (PAL) activity, PAL gene expression, and skin epicatechin content; (ii) percentage of ready-to-eat stage fruit; (iii) changes in targeted phenolic compounds and C7 sugar (D-mannoheptulose); and (iv) phytonutritional changes to replace the currently commercially used Prochloraz application.

\section{Materials and Methods}

\subsection{Chemicals and Reagents}

Chemical standards; D-mannoheptulose; pyrogallol; epicatechin; catechin; and gallic, vanillic, protocatechuic, syringic, chlorogenic, 2,5-dihydroxybezoic, $p$-coumaric, ellagic acids at $>95-98 \%$ purity and other chemicals were purchased from Sigma-Aldrich (Johannesburg, South Africa). For gene expressions, the LunaScript RT SuperMix, Luna Universal qPCR Master Mix, and ZR RNA MiniPrep kits were purchased from Epigenetics Company (Johannesburg, South Africa), whilst primer sequences for actin, lipoxygenase $(L O X)$, phenylalanine ammonia lyase $(P A L)$, chitinase $(C H I)$, and $\beta$-1,3-glucanase $(G L U)$ genes were obtained from Inqaba Biotechnical Industries (Pty) Ltd., Pretoria, South Africa.

\subsection{Anthracnose Incidence in Inoculated Avocados}

Avocado fruit cvs. Fuerte and Hass, harvested at 67 and 70\% moisture content, were sorted according to the quality standards at the Bassan Packers in Tzaneen, South Africa. Each fruit weighed between 249 and $289 \mathrm{~g}$, and a set of 200 fruit per each cultivar were brought to the laboratory, ripened at $25{ }^{\circ} \mathrm{C}$ and $85 \% \mathrm{RH}$ within two days to reach the trigger-ripe stage at finger feel firmness stage 2 (firmness $\geq 1.5 \mathrm{~kg} ; 1=$ hard, $2=$ slightly soft, just starting to ripen, $3=$ very soft). Prior to the artificial inoculation, fruit were surface sterilised with $0.1 \mathrm{~mL} \mathrm{~L}^{-1} \mathrm{NaOCl}$ for $5 \mathrm{~min}$, and the fruit surfaces of both avocado cultivars were wounded ( $2 \mathrm{~mm}$ deep and $6 \mathrm{~mm}$ wide) with a sterilised 
cork-borer and inoculated with $20 \mathrm{~L}$ of a spore suspension of C. gloeosporioides spore suspension $\left(10^{6}\right.$ spores $\left.\mathrm{mL}^{-1}\right)$, as previously described by Obianom et al. [13]. After incubating the fruit for $16 \mathrm{~h}$ after inoculation, the fruit was packed in polystyrene trays and wrapped with macro perforated (atmosphere gas composition) biaxially oriented polypropylene (BOPP) film to reduce moisture loss. Ten replicate tray packs, each containing four fruit, were placed in a random position, directly exposing the inoculated site, and subsequently exposed to the following postharvest treatments: (i) red LED $\left(660 \mathrm{~nm}, 150 \mu \mathrm{mol} \mathrm{m}^{-2} \mathrm{~s}^{-1}\right)$ [10] for $6 \mathrm{~h}$ per day (as per preliminary experiments); (ii) blue LED (450 nm, $100 \mu \mathrm{mol} \mathrm{m}{ }^{-2} \mathrm{~s}^{-1}$ ) [10] for $6 \mathrm{~h}$ per day (as per preliminary experiments); (iii) commercial control Prochloraz (450 g L $\mathrm{g}^{-1}$; imidazole) (Adama SA (Pty) Ltd., Cape Town, South Africa) at $12{ }^{\circ} \mathrm{C}$ for 4,8 , 12 , or 16 days to simulate market shelf conditions. The shelves were fitted with LED lights and the distance between the fruit and the LED lights was $100 \mathrm{~mm}$. Thereafter, the fruit were held at $25^{\circ} \mathrm{C}$ for 2 days for the development of anthracnose incidence, and the results were expressed in percentages.

\subsection{Gene Expression in Avocado Cultivars}

Gene expression was performed using fruit skin (10 $\mathrm{mm}$ around the inoculated area) diced into pieces, snap-frozen in liquid nitrogen, and stored at $-80^{\circ} \mathrm{C}$. The gene expression determined was according to the method of Obianom et al. [13] with RT-qPCR using a SYBR green dye system without any modifications. To extract the total RNA in avocado pulp, using a MiniPrep kit, involved using a volume of $500 \mathrm{mg}$ of fruit skin. In total, $1 \mu \mathrm{L}$ of RNA was used for cDNA synthesis with reverse transcription PCR, using LunaScript RT SuperMix cDNA synthesis kits, according to the manufacturer's instructions. The selected genes included those coded for the endogenous control gene (actin), pathogenesis-related protein (chitinase and $\beta-1,3$-glucanase), and PAL and LOX sequence of Persea americana deposited in NCBI GenBank. The actin was used as a house-keeping gene in this study.

\subsection{Naturally Infected Fruit and Incidence of Anthracnose}

As reported in Section 2.2, 10 replicate punnets exposed to three different postharvest treatments were subsequently stored at $12{ }^{\circ} \mathrm{C}$ and $78 \% \mathrm{RH}$ for $4,8,12$, or 16 day to simulate the commercial market shelf conditions. After being removed from the shelf at designated intervals, fruit were kept for an additional 5 days to determine the (i) number of days taken to reach ready-to-eat stage, (ii) anthracnose incidence, and (iii) biochemical characteristics.

A set of 10 fruit per treatment (i.e., one fruit from each punnet) was taken for biochemical analysis. After cutting the fruit into pieces, it was mixed together and frozen at $-80^{\circ} \mathrm{C}$. A set of six samples from the cumulative sample were used for biochemical analysis to reduce the variation. Thereafter, fruit were frozen and freeze-dried using a Virtis SP Scientific with Sentry 2.0 controller (SP Scientific, New York, NY, USA) equipped with condenser at $-59.6^{\circ} \mathrm{C}$ and vacuum at $62 \mathrm{mT}$ before being ground to powder for analysis of phenolic metabolites.

\subsection{Percentage of Ripe and Ready-to-Eat Stage Fruit under Different Postharvest Treatments and Storage Periods}

The percentage of fruit that reached ready-to-eat ripe stage (firmness of less than $1.0 \mathrm{~kg}$ ) was determined for both avocado cultivars. Fruit firmness was determined at two points of the equatorial area by the puncture method using a penetrometer, with a puncture (or penetrometer) test using a $6.35 \mathrm{~mm}$ diameter flat-head stainless-steel probe with a conical tip (Chatillon DFG 50, John Chatillon \& Sons, Inc., New York, NY, USA) driven $8 \mathrm{~mm}$ into the fruit (skin intact) at a speed of $180 \mathrm{~mm} \mathrm{~min}{ }^{-1}$. The advantage of using a conical probe is that fruit firmness is measurable without needing to remove the skin [14]. 


\subsection{Biochemical Analysis}

\subsubsection{D-Mannoheptulose (C7 Sugar) Content}

D-mannoheptulose content was determined according to Glowacz et al. [15] and Mapi and Sivakumar [16], without any modifications, using avocado pulp powder $(100 \mathrm{mg})$ dissolved in $1.4 \mathrm{~mL}$ of methanol and $50 \mu \mathrm{L}$ of an internal standard (ribitol $2 \mathrm{~g} \mathrm{~L}^{-1}(w / v)$ in water). D-mannoheptulose content was quantified using GC-MS system 7890A gas chromatograph equipped with an MS (5975C VL0) detector (Agilent Technologies, Johannesburg, South Africa). The GC conditions and run parameters were set up according to Glowacz et al. [15].

\subsubsection{Extraction and Quantification of Fruit Metabolites}

Extraction of untargeted phenolic metabolites was as per the following method described by Mpai and Sivakumar [17] without any modifications. Two grams of fruit pulp and $2 \mathrm{~mL}$ acidified methanol containing $80 \%$ methanol, $19.5 \%$ distilled water, and $0.5 \% \mathrm{HCl}$ were mixed in a thermostatic shaking water bath at $70{ }^{\circ} \mathrm{C}$ for $30 \mathrm{~min}$. Subsequently, the mixture was centrifuged at 10,000 rpm for $15 \mathrm{~min}$ at $4{ }^{\circ} \mathrm{C}$, and the supernatant was filtered through Whatman No. 1 filter paper. The pooled filtrates were dried under $\mathrm{N}_{2}$ gas flow at $35{ }^{\circ} \mathrm{C}$ and then resuspended with $1.5 \mathrm{~mL}$ of extraction solution prior to targeted metabolite analysis. Metabolite profiling of avocado cultivars was carried out adopting a method similar to that described by Mpai and Sivakumar [16]. Waters Acquity Ultra Performance Liquid Chromatographic (UPLC) system attached to a PDA detector (Waters, Milford, MA, USA) equipped with an Acquity UPLC HSS C18 column $(150 \times 2.1 \mathrm{~mm}, 1.8 \mu \mathrm{m}$ particle size, Waters) was used for the detection and quantification of the phenolic metabolites. Mobile phases A and $\mathrm{B}$ consisted of water with $0.1 \%$ formic acid and acetonitrile, respectively. Optimum separation was achieved using gradient elution executed as follows: $0 \mathrm{~min}, 95 \% \mathrm{~A}$ and $5 \% \mathrm{~B} ; 1 \mathrm{~min}, 85 \% \mathrm{~A}$ and $15 \% \mathrm{~B}$; $15 \mathrm{~min}, 5 \% \mathrm{~A}$ and $95 \% \mathrm{~B}$; coming back to the initial condition and being calibrated. The flow rate used was $0.3 \mathrm{~mL} \mathrm{~min}^{-1}$ at $30^{\circ} \mathrm{C}$ and injection volume was $2.0 \mu \mathrm{L}$ (full-loop injection). Chromatographic software Masslynx 4.1 processed and obtained all the chromatographic data. Since it was difficult to purchase authentic standards, catechin $\left(Y=24.4855 x+246.089, r^{2}=0.99\right)$ was to quantify the flavonoids, such as feruloyl-quinic acid, coumaric glucose, and tryptophan. All chromatography operations were performed at ambient temperature, in triplicate, and coumaric acid hexoside $(325.091 \mathrm{~m} / \mathrm{z} ; 11.1 \mathrm{RT})$, 4-feruloyl quinic acid (367.1025 m/z; $14.44 \mathrm{RT})$, and tryptophan (203.0825 m/z; $8.46 \mathrm{RT})$ were expressed in milligrams per kilogram on a dry fresh weight basis.

\subsubsection{Fatty Acid Composition}

Fatty acid composition was determined according to the method described by Glowacz et al. [15], using avocado pulp $(1 \mathrm{~g})$ and homogenising with $30 \mathrm{~mL}$ of hexane for $30 \mathrm{~s}$. Oil extraction was performed following the method used by Meyer and Terry [17], without any modifications. After dissolving the derived avocado oil extract in $2 \mathrm{~mL}$ of hexane and mixing with $0.2 \mathrm{~mL}$ of $0.2 \mathrm{~mol} \mathrm{~L}^{-1}$ potassium hydroxide in methanol, the mixture underwent vigorous shaking for $30 \mathrm{~s}$. The upper hexane layer containing methyl esters was decanted and diluted 1:100 $(v / v)$ with n-hexane directly prior to injection into the GC-MS system (7890A gas chromatograph equipped with an MS (5975C VL0) detector (Agilent Technologies, Johannesburg, South Africa)). The conditions for the GC-MS system were similar to those of Glowacz et al. [15], with the fatty acids expressed in milligrams per gram.

\subsubsection{Ascorbic Acid Content}

Ascorbic acid content was determined using the 2,6-dichlorophenolindophenol dye titration method described for the different samples. These results were expressed as grams per kilogram on a fresh weight basis [18]. 


\subsubsection{The 2,2,1-Diphenyl-1-Picrylhydrazyl (DPPH) Radical Scavenging Assay}

The DPPH assay was determined according to the method described by Tinyane et al. [19], and the results were expressed as the concentration of antioxidants required to decrease the initial DPPH absorbance by $50 \%\left(\mathrm{IC}_{50}\right)$ in milligrams of gallic acid equivalent per gram of fruit.

\subsection{Statistical Analysis}

Assessments of the studied quality attributes and biochemical parameters were conducted following a two-factorial type, which consisted of three postharvest treatments (red LED, blue LED, and commercial condition (prochloraz + darkness)) and four storage periods (days 4, 8, 12, and 16) of storage separately for cvs. Fuerte and Hass displayed in a completely randomised design. Data were subjected to a two-way analysis of variance (light treatment $\times$ days of exposure) (ANOVA) at Fisher's protected least significant difference at $p<0.05$ level, using Genstat (for Windows 08, version 64-bit Release 18:2, International Ltd., England, UK) package to obtain the mean values for the interaction of "light treatment and days of exposure". There was no significant difference on single factor "light treatment" or "days of exposure". During the growing season, the experiment was repeated three times.

\section{Results}

\subsection{Effect of LED Light Treatments on Incidence of Anthracnose in Inoculated Avocado Cultivars}

Inoculated cv. Fuerte exposed to red LED light showed 32\% anthracnose incidence on day 4 in storage, whereas fruit exposed to blue LED light or treated with commercial fungicide showed 42 and $40 \%$ anthracnose incidence, respectively. Conversely, inoculated fruit exposed to red LED light and stored for 8 and 12 days showed significantly lower anthracnose incidence $(25 \%)$ compared to the fruit exposed to blue LED light or treated with commercial fungicide (Figure 1A). On day 16, fruit exposed to red LED light showed $40 \%$ anthracnose incidence, whereas the inoculated fruit exposed to blue LED light or treated with commercial fungicide showed the highest anthracnose incidences of 60 and $56 \%$, respectively (Figure 1A).

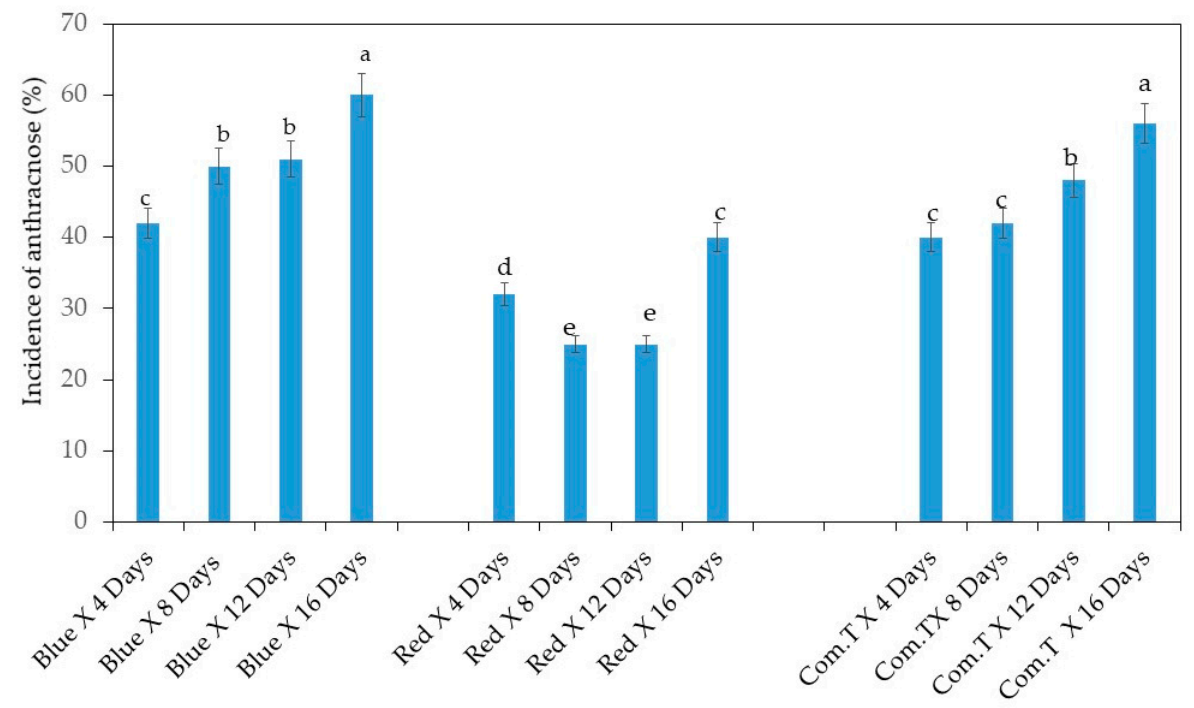

(A)

Figure 1. Cont. 


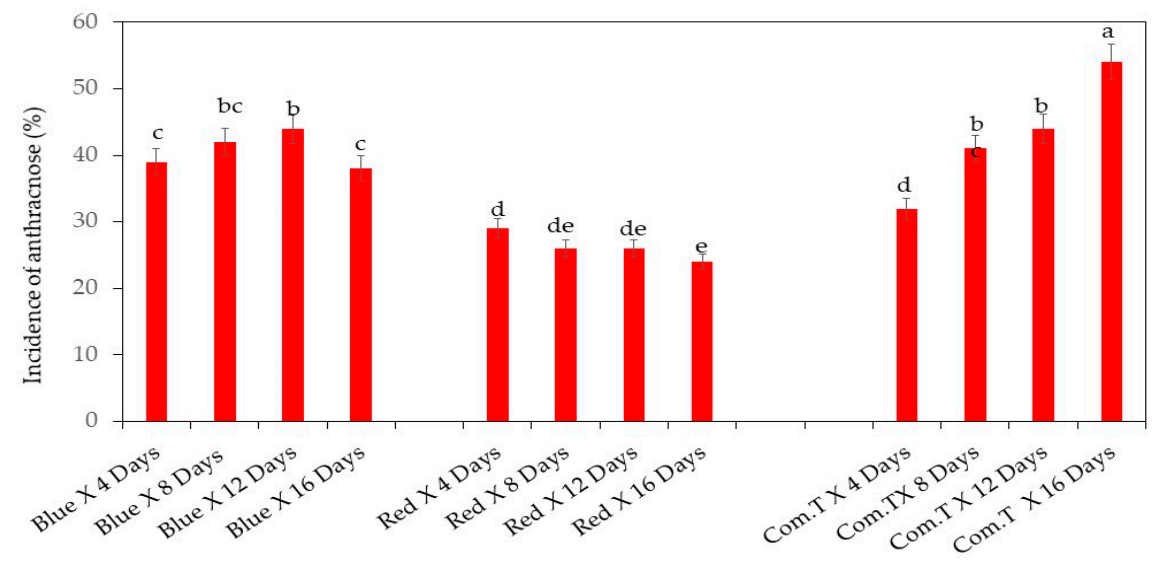

(B)

Figure 1. (A) Influence of light-emitting diode (LED) light exposure on inoculated avocado cultivar Fuerte. (B) Influence of LED light exposure on inoculated avocado cultivar Hass. The exposure of the fruit to blue or red LED light was for $6 \mathrm{~h}$ per day during storage. Ten replicate tray packs, each containing four fruit, underwent different postharvest treatments. Mean values of bars marked by different letters were significantly different at $p<0.05$, according to Fisher's protected LSD test. Blue, blue LED light; Red, red LED light; Com.T, commercial treatment.

Inoculated cv. Hass, exposed to red LED light or treated with commercial fungicide showed more or less similar anthracnose incidence (30 to $32 \%$ ) on day 4 in storage, whilst the fruit exposed to blue LED light showed higher (42\%) anthracnose incidence (Figure 1B). At the same time, significantly lower anthracnose incidence was observed in inoculated fruit exposed to red LED on days 8, 12, and 16 in storage compared to fruit exposed to blue LED light or treated with commercial fungicide and stored for the respective periods. The highest anthracnose incidence (54\%) appeared in inoculated fruits treated with commercial fungicide and held in storage for 16 days (Figure 1B).

\subsection{Effect of LED Light Treatments on Incidence of Anthracnose in Naturally Infected Avocado Cultivars}

The lowest anthracnose incidence $(\leq 25 \%)$ was observed in naturally infected cv. Fuerte exposed to red LED light and stored up to 4, 8, and 12 days when compared to blue LED light or commercial fungicide treatment (Figure 2A). Highest anthracnose incidence was on day 16 in fruit exposed to blue LED light ( $50 \%$ incidence) or treated with commercial fungicide treatment ( $54 \%$ incidence) (Figure $2 \mathrm{~A}$ ).

In naturally infected cv. Hass, red LED light exposure significantly reduced the anthracnose incidence to $12 \%$ in fruit stored up to 8,12 , and 16 days when compared with the blue LED and commercial fungicide treated fruit (Figure 2B). Cultivar Hass stored up to 4 days showed $\sim 20 \%$ anthracnose incidence, whilst fruit exposed to blue LED light or treated with commercial fungicide showed 36 and 30\% anthracnose incidence, respectively. Significantly highest anthracnose incidence $(47 \%)$ was observed on day 16 in fruit exposed to blue LED light (Figure 2B). The key finding is that employing red LED light exposure for $6 \mathrm{~h}$ per day and storage for 8 or 12 days can reduce the anthracnose incidence in green thin-skinned cultivar Fuerte for marketing. Similar postharvest treatment can be recommended to reduce the anthracnose incidence in dark-skinned cultivar Hass for fruit stored after treatment for 8,12 , and 16 days. 


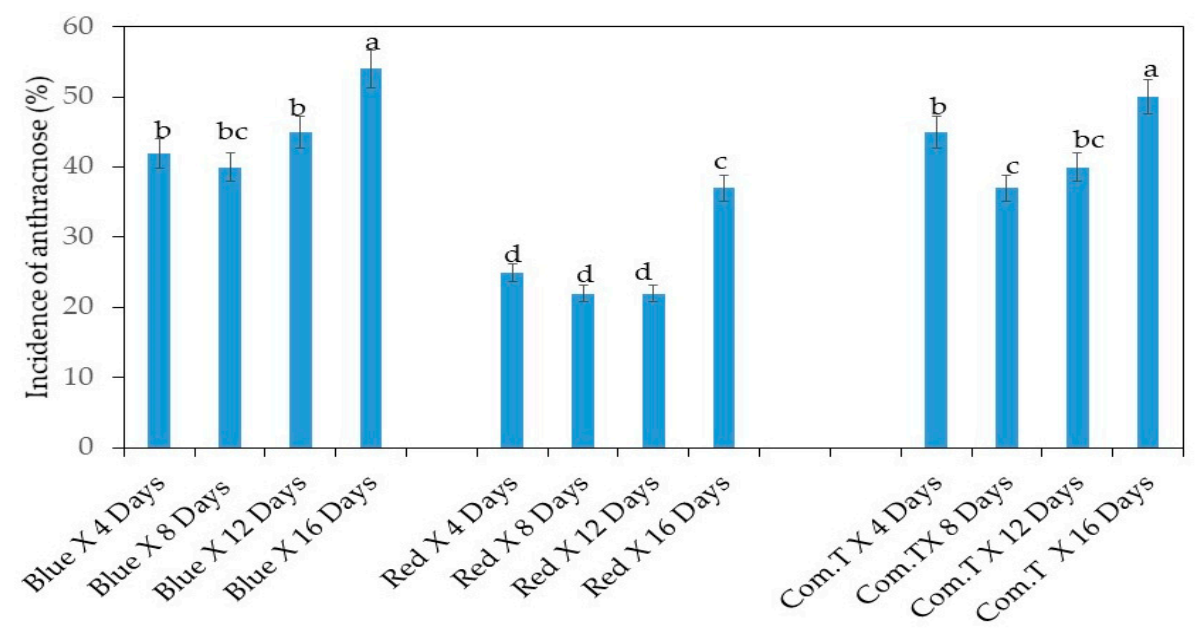

(A)

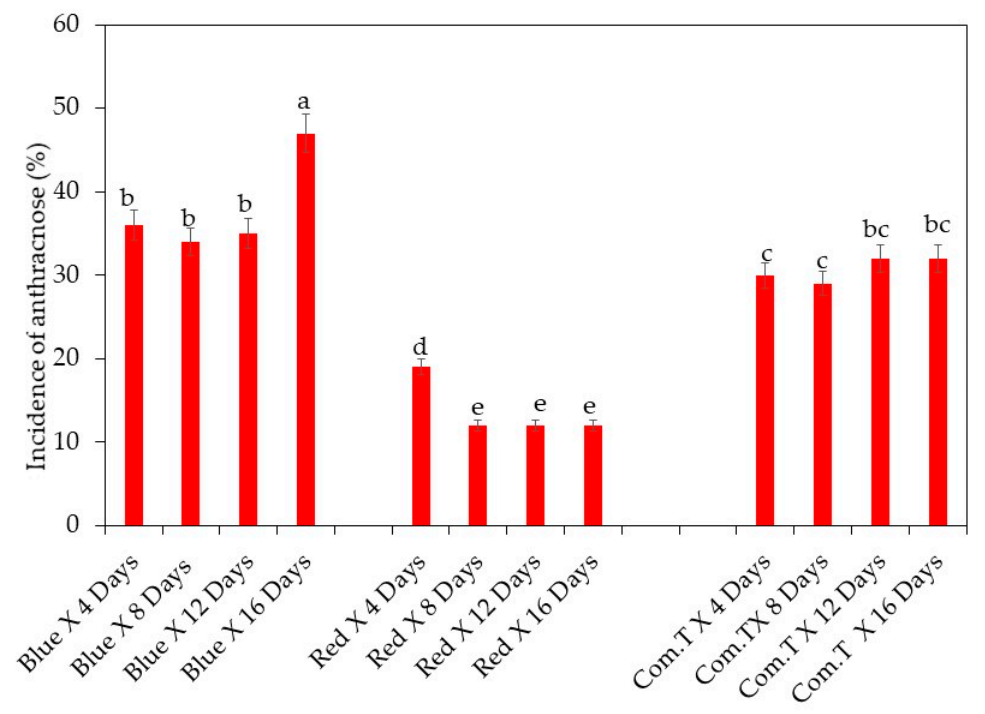

(B)

Figure 2. (A) Influence of LED light exposure on naturally infected avocado cultivar Fuerte. (B) Influence of LED light exposure on naturally infected avocado cultivar Hass. The exposure of fruit to blue or red LED light was for $6 \mathrm{~h}$ per day during storage. Ten replicate tray packs, each containing four fruit, underwent different postharvest treatments. Mean values of bars marked by different letters were significantly different at $p<0.05$, according to Fisher's protected LSD test. Blue, blue LED light; Red, red LED light; Com.T, commercial treatment.

\subsection{Effect of LED Light Treatments on PAL and LOX Gene Expression and Exocarp Epicatechin Content}

Significantly highest upregulation of $P A L$ genes was observed in cv. Fuerte exposed to red LED light and stored up to 12 days compared to the fruit stored for 4, 8, and 16 days (Figure 3A). Simultaneously, cv. Fuerte exposed to red LED light showed the significantly highest upregulation of $P A L$ genes compared to the fruit exposed to blue LED light or commercial fungicide treatment in storage for $4,8,12$, and 16 days (Figure $3 \mathrm{~A}$ ).

Similarly, the highest upregulation of $P A L$ genes was noted in cv. Hass fruit exposed to red LED light and stored up to 12 days, but the level of upregulation of $P A L$ genes was higher in $\mathrm{cv}$. Hass when compared to cv. Fuerte (Figure 3B). Furthermore, red LED light exposure also showed a 
higher upregulation of $P A L$ genes in fruit stored up to 8 and 16 days than in fruit exposed to blue LED light or treated with commercial fungicide and stored for similar storage periods (Figure 3B).

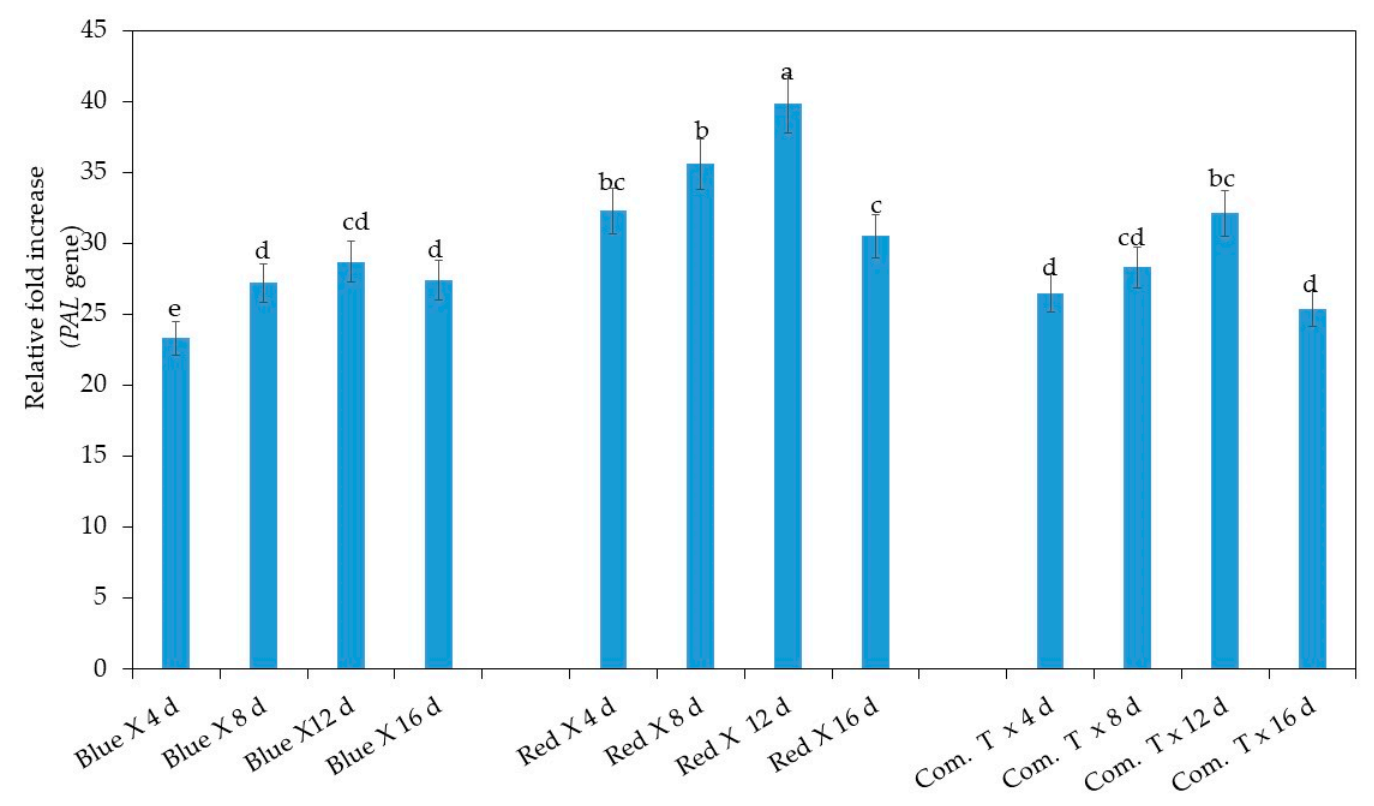

(A)

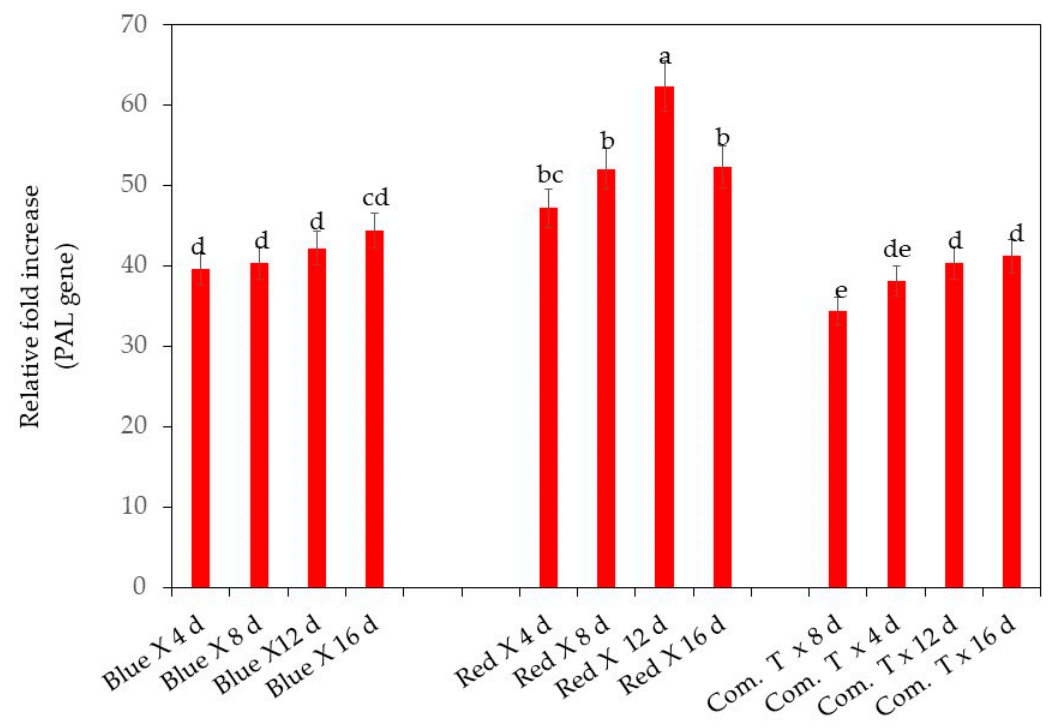

(B)

Figure 3. (A) Influence of LED light exposure on $P A L$ (phenylalanine ammonia lyase gene expression) in avocado cultivar Fuerte. (B) Influence of LED light exposure on PAL (phenylalanine ammonia lyase gene expression) in avocado cultivar Hass. The exposure of the fruit to blue or red LED light was for $6 \mathrm{~h}$ per day during storage. Number of replicates per treatment $n=5$. Mean values of bars marked by different letters were significantly different at $p<0.05$, according to Fisher's protected LSD test. Blue, blue LED light; Red, red LED light; Com. T, commercial treatment.

Significantly higher epicatechin content in the pericarp was detected in cv. Fuerte exposed to red LED light and stored for 8 and 12 days when compared to the fruit stored for 4 and 16 days (Figure 4A). It is interesting to note that cv. Fuerte exposed to red LED light and stored for 8 and 
12 days showed higher epicatechin content than the fruit exposed to blue LED light or treated with commercial fungicide and stored for 4, 8, 12, and 16 days (Figure 4A).

Cultivar Hass exposed to red LED light significantly retained the highest epicatechin content in the pericarp at 12 days of storage, followed by the fruit kept on the shelf for 8 days, when compared to the other two treatments at similar storage periods (Figure 4B).

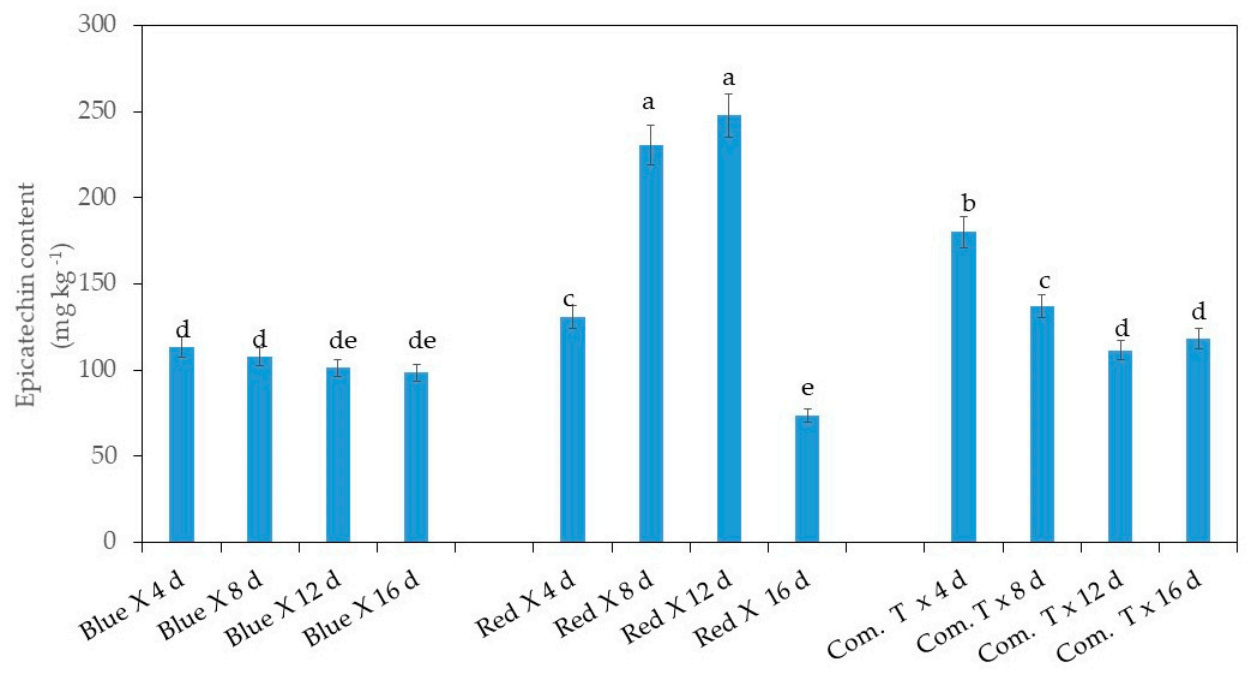

(A)

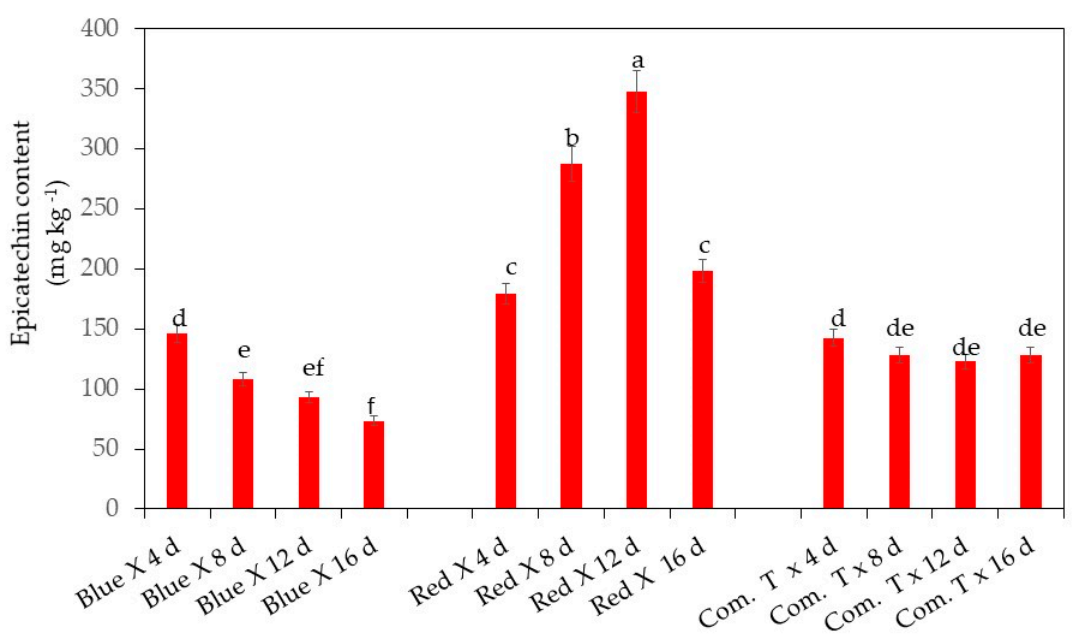

(B)

Figure 4. (A). Influence of LED light exposure on skin epicatechin content in avocado cultivar Fuerte. (B). Influence of LED light exposure on skin epicatechin content in avocado cultivar Hass. The exposure of fruit to blue or red LED light was for $6 \mathrm{~h}$ per day during storage. Number of replicates per treatment $n=5$. Mean values of bars marked by different letters were significantly different at $p<0.05$, according to Fisher's protected LSD test. Blue, blue LED light; Red, red LED light; Com. T, commercial treatment.

Overall, cv. Fuerte exposed to LED light and stored for 4, 8, 12, and 16 days showed significantly lower upregulation of $L O X$ gene expression when compared to the other two postharvest treatments and similar storage periods, as shown in Figure 5A. The highest upregulation of LOX gene expression was noted in fruit treated with commercial fungicide and stored for 16 days. In general, all the fruit treated with commercial fungicide showed significantly higher gene expression compared to the fruit exposed to the blue LED light and stored at the respective storage periods. 
Likewise, in cv. Hass, exposure to red LED light significantly reduced the upregulation of LOX when compared with the fruit exposed to blue LED light or treated with commercial fungicide and stored at $4,8,12$, and 16 days (Figure $5 B$ ).

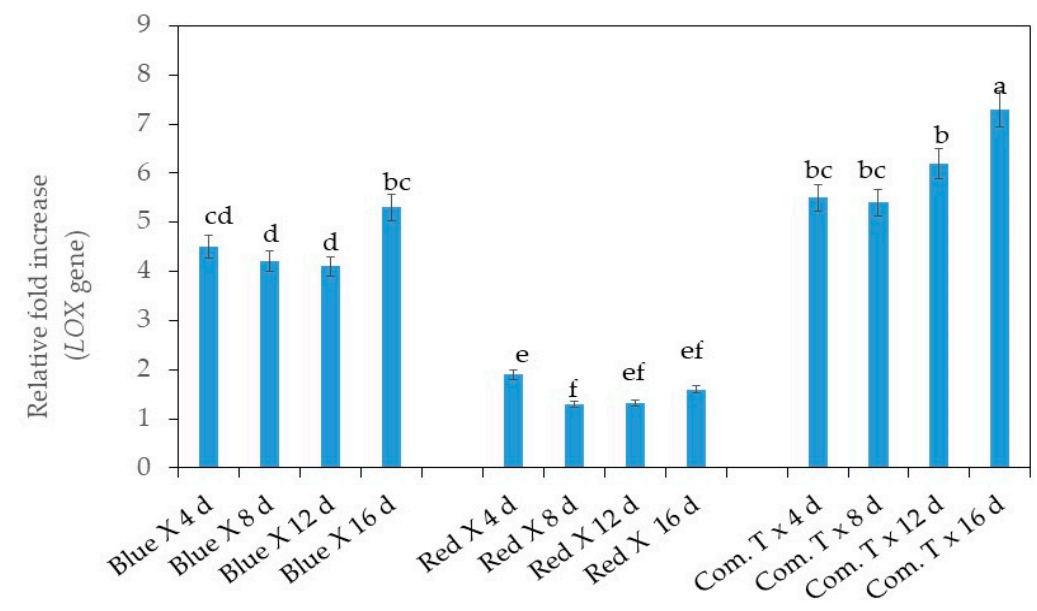

(A)

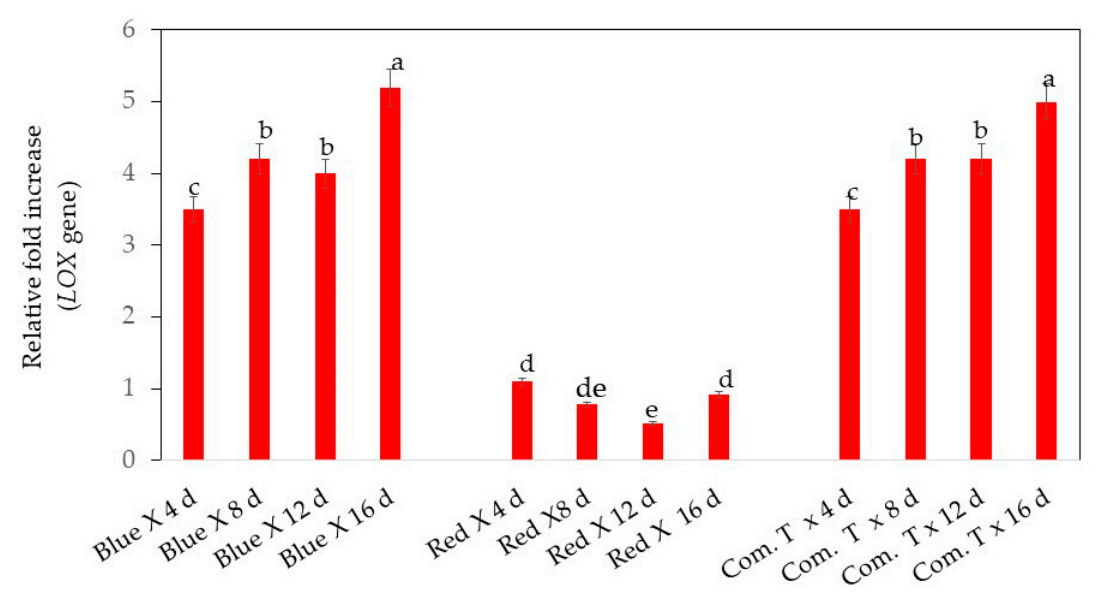

(B)

Figure 5. (A). Influence of LED light exposure on LOX (lipoxygenase) gene expression in avocado cultivar Fuerte. (B). Influence of LED light exposure on LOX (lipoxygenase) gene expression in avocado cultivar Hass. The exposure of fruit to blue or red LED light was for $6 \mathrm{~h}$ per day during storage. Number of replicates per treatment $n=5$. Mean values of bars marked by different letters were significantly different at $p<0.05$, according to Fisher's protected LSD test. Blue, blue LED light; Red, red LED light; Com. T, commercial treatment.

\subsection{Effect of LED Light Treatments on Coumaric Acid Hexoside, 4-Feruloyl Quinic Acid,} and Tryptophan Content

UPLC-QTOF/MS analysis helped to detect the coumaric acid hexoside, 4-feruloyl quinic acid, and tryptophan in avocado cvs. Fuerte and Hass after storage. Overall, cv. Fuerte treated with commercial fungicide and stored for 12 to 16 days or exposed to blue LED treatments and stored for 8 to 12 days showed higher concentrations of coumaric acid hexoside (Figure 6A). The highest concentration of coumaric acid hexoside was detected in fruit that underwent commercial fungicide treatment and was stored up to 12 days (Figure 6A). Conversely, fruit exposed to red LED light 
retained lower concentrations of coumaric acid hexoside throughout the storage time, and the lowest concentration was detected on day 12 (Figure 6A).

Similar reduced concentration of coumaric acid hexoside was found in $\mathrm{cv}$. Hass exposed to red LED light in different storage periods $(4,8,12$, and 16 days) compared to the other two postharvest treatments. The significantly lowest concentrations of coumaric acid hexoside were found in red LED light exposed cv. Hass stored for 12 and 16 days (Figure 6B).

Conversely, the significantly lowest concentrations of 3-feruloyl quinic acid were in cv. Fuerte fruit exposed to red LED light treatment and stored for 12 and 16 days (Figure $6 \mathrm{C}$ ) when compared to the fruit treated with commercial fungicide or exposed to blue LED light and stored for similar extended storage periods. (Figure 6B). Red light exposure showed a similar trend in cv. Hass, but significantly lowest concentrations of 3-feruloyl quinic acid were found in fruit exposed to red LED light and stored for 8 and 12 days when compared to all other postharvest treatments adopted in this study (Figure 6D).

Tryptophan amino acid accumulation was highest in cultivar Fuerte on day 12 in fruit exposed to red LED light compared to the fruit exposed to blue LED light or treated with commercial fungicide (Figure 6E). In cv. Hass, the highest accumulation of tryptophan was in fruit exposed to red LED light and stored for 8 and 12 days when compared to the fruit that underwent the other two postharvest treatments and was stored at different storage periods (Figure 6F). 

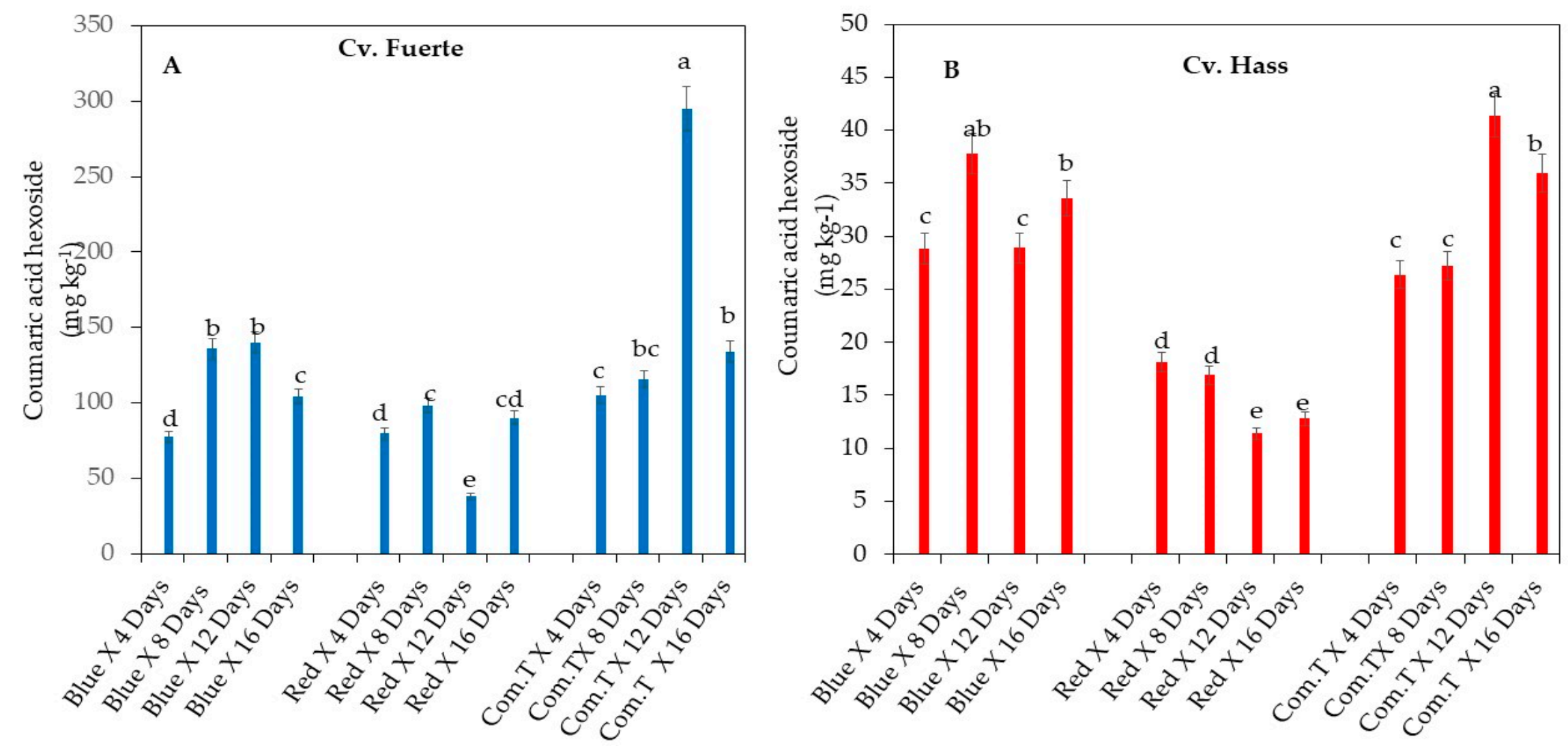

Figure 6. Cont. 


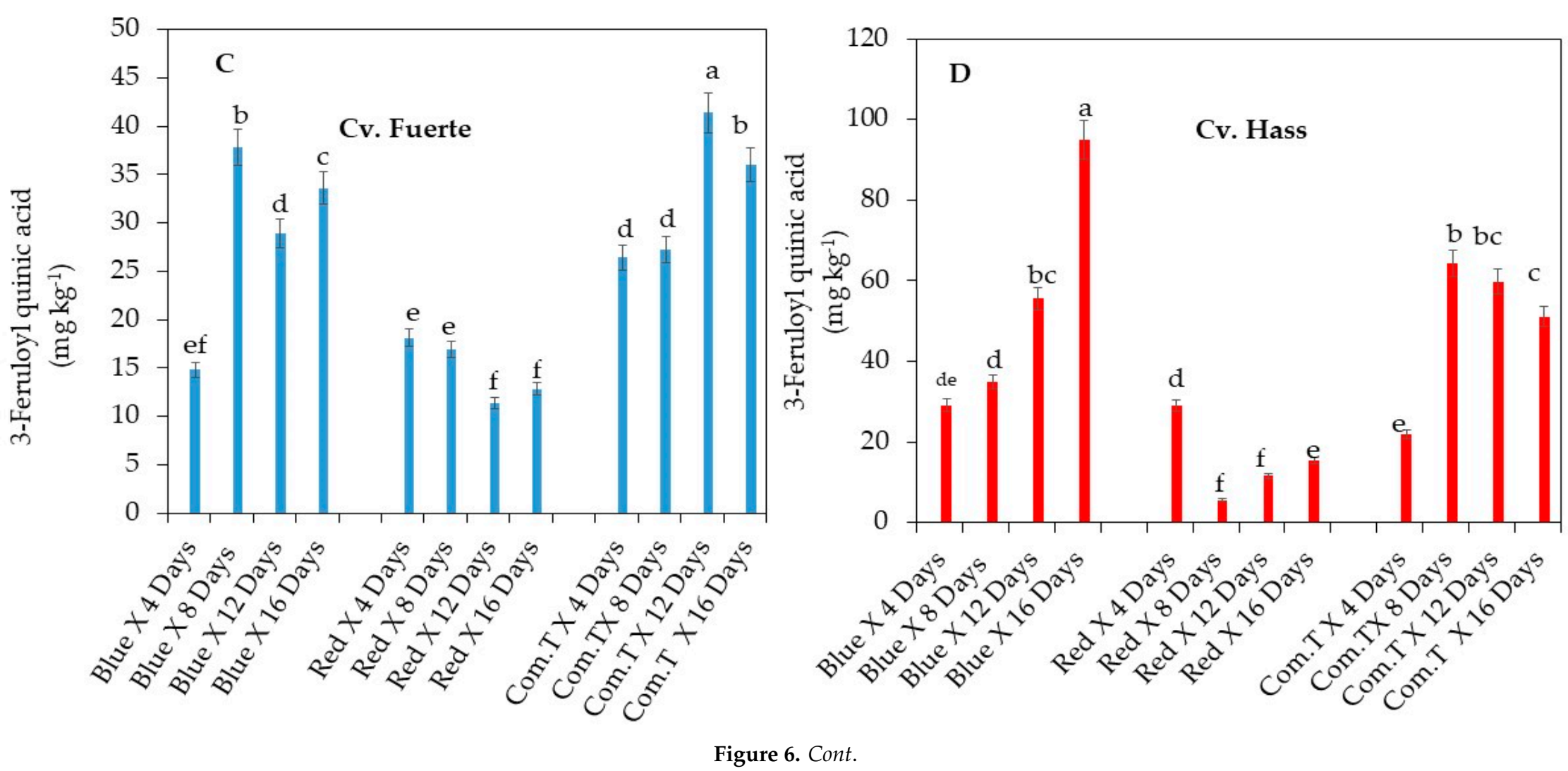



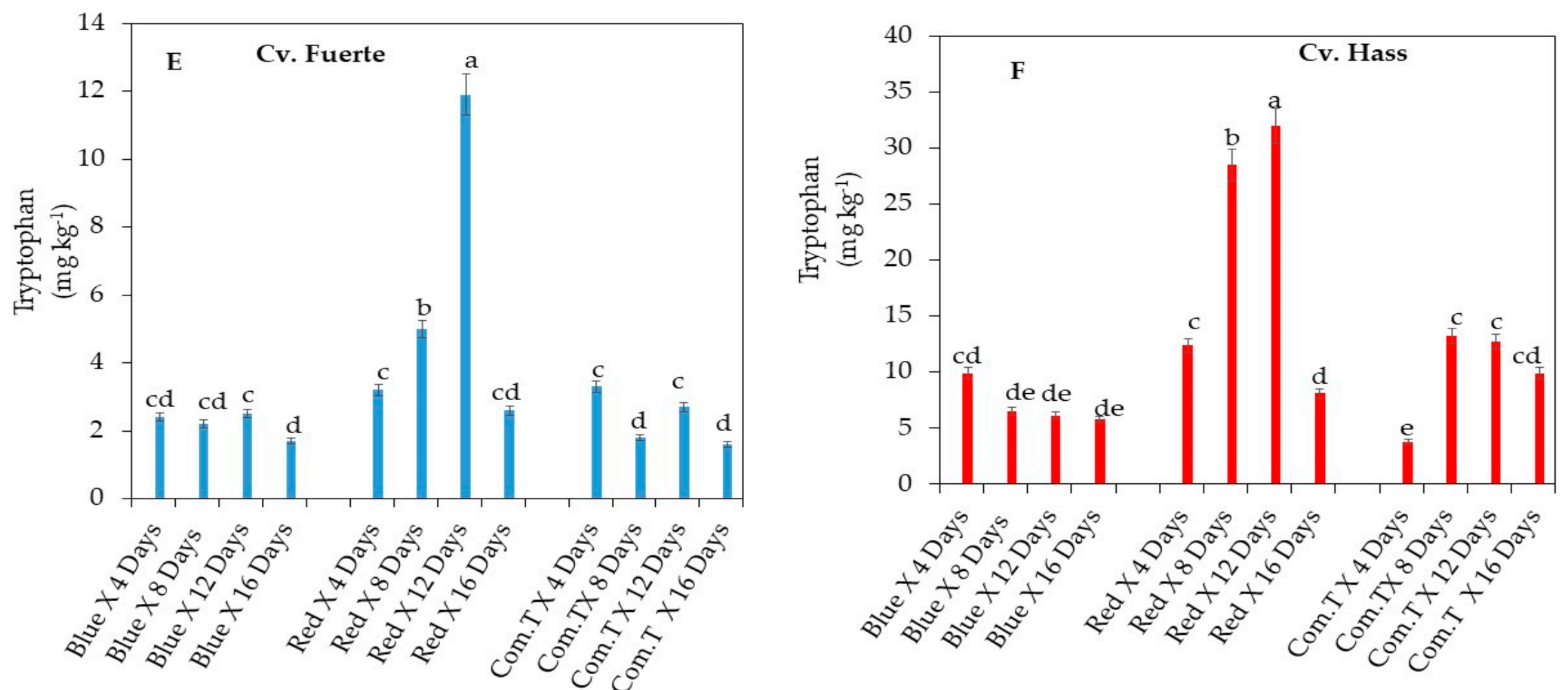

Figure 6. Influence of LED light treatments on (A) coumaric acid hexoside in cv. Fuerte and (B) coumaric acid hexoside in cv. Hass. Influence of LED light treatments on (C) 3-feruloyl quinic acid in cv. Fuerte and (D) 3-feruloyl quinic acid in cv. Hass. Influence of LED light treatments on (E) tryptophan in cv. Fuerte and (F) tryptophan in cv. Hass. Mean \pm standard deviation values for each bar were calculated based on five fruits. Number of replicates per treatment $n=5$. Mean values of bars marked by different letters were significantly different at $p<0.05$, according to Fisher's protected LSD test. Blue, blue LED light; Red, red LED light; Com.T, commercial treatment. 


\subsection{Effect of LED Light Treatments on Percentage of Fruit Reaching Ready-to-Eat Stage}

Cultivar Fuerte fruit exposed to red LED light and stored for 12 days were significantly firm when compared to the fruit exposed to blue LED light or commercial fungicide treatment and stored for a similar storage period (Figure 7A). Overall, the percentages of firm fruit obtained from red LED light treatment and storage periods of 8,12 , and 16 days were significantly higher when compared to those of the other two postharvest treatments. Approximately 70 to $80 \%$ firm fruit were obtained from red LED light treatment and 8 to 12 days cold shelf storage (Figure 7A). Exposure to blue LED light showed 11,20 , and $40 \%$ overripe fruit after 8,12 , and 16 days of cold storage, respectively. Moreover, $30 \%$ of cv. Fuerte fruit became overripe after commercial fungicide treatment and 16 days of cold shelf storage (Figure 7A). The significantly highest percentages (65 to 70\%) of ready-to-eat ripe stage were obtained from blue LED light treatment ( 8 and 12 days storage periods), red LED light treatment (4 days storage) and commercial fungicide treatment (16 days storage).

A similar ripening trend was observed in cv. Hass as well, with the fruit exposed to red LED light and stored for 8,12 , and 16 days being firmer than fruit that underwent other postharvest treatments and were stored at different storage periods (Figure 7B). Approximately 70 to $75 \%$ of cv. Hass fruit exposed to red LED and stored for 8 to 16 days were firmer when compared to the fruit from blue LED light or chemical fungicide treatment (Figure 7B). Conversely, commercial fungicide treated fruit stored for 12 days or fruit exposed blue LED light and stored up to 8 days showed the highest percentages of ready-to-eat stage ripe fruit. Furthermore, cv. Hass fruit exposed to blue LED light and stored for 12 and 16 days showed around 22 to $28 \%$ overripe fruits, and commercial fungicide treated fruit stored for 16 days also showed $30 \%$ overripe fruit.

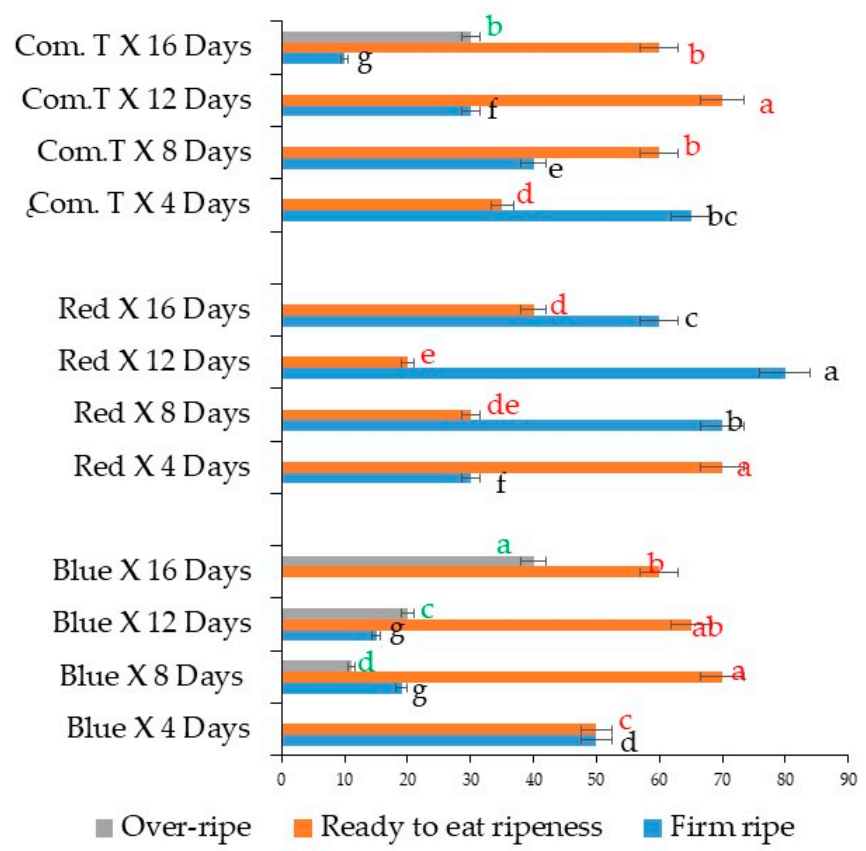

(A)

Figure 7. Cont. 


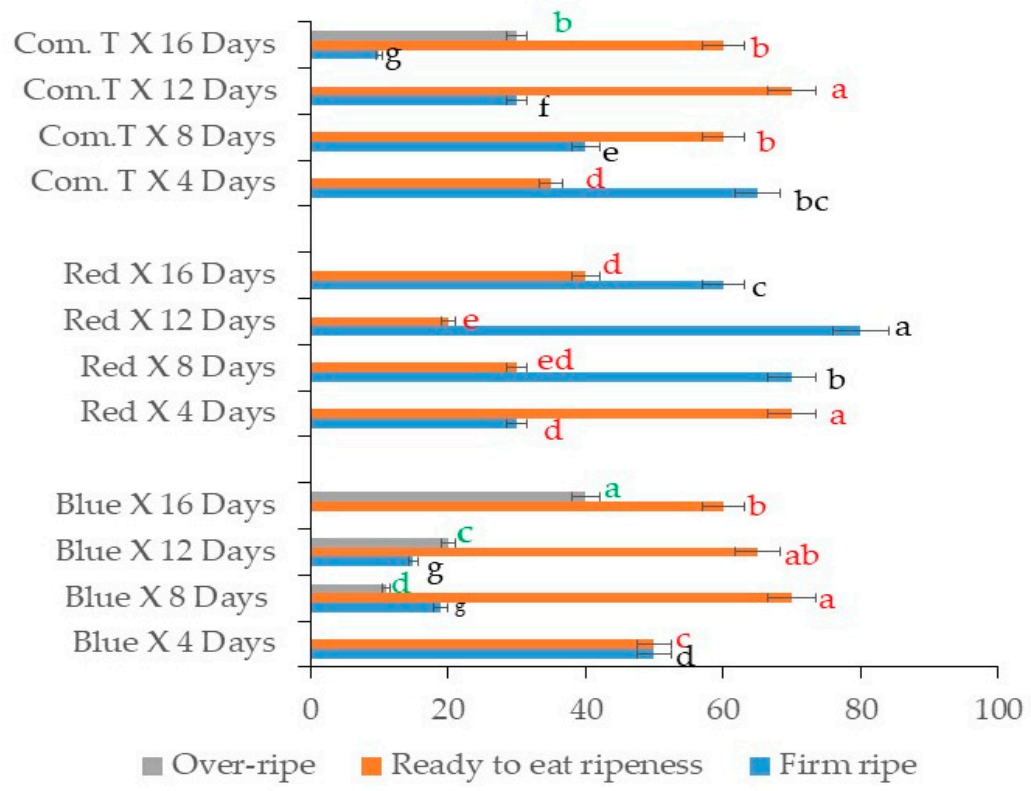

(B)

Figure 7. (A) Influence of LED light treatment on ripening in avocado cultivar Fuerte. (B) Influence of LED light treatment on ripening in avocado cultivar Hass. Fruit were exposed to blue or red LED light for $6 \mathrm{~h}$ per day during storage and left at $25^{\circ} \mathrm{C}$ for 2 days after storage. Mean values for each bar were calculated based on 100 fruits for each treatment. Bars with similar letters were not significantly different at $p<0.05$ according to LSD. Blue, blue LED light; Red, red LED light; Com. T, commercial treatment.

\subsection{Effect of LED Light Treatments on D-Mannoheptulose Content}

The D-mannoheptulose content was significantly highest in cv. Fuerte exposed to red LED light and stored for 12 days when compared to the other two postharvest treatments and at similar storage periods (Figure 8A). Fruit exposed to red LED light and stored for 8 and 16 days and commercial fungicide treated fruit stored for 4 days showed higher concentrations of D-mannoheptulose sugar than the other counterpart treatments and storage periods. It is interesting to note that the fruit exposed to blue LED light for 12 and 16 days or commercial fungicide treated fruit stored for 12 and 16 days showed significantly lower concentrations of D-mannoheptulose sugar (Figure 8A).

Cultivar Hass exposed to red LED light and stored for 8, 12, and 16 days showed significantly higher and similar D-mannoheptulose content compared to the commercial fungicide treated fruit stored 4 days on the cold shelf (Figure $8 \mathrm{~B}$ ). However, cv. Hass exposed to blue LED light and stored for 16 days showed the highest D-mannoheptulose content compared to the other two postharvest treatments and storage periods (Figure $8 \mathrm{~B}$ ). 


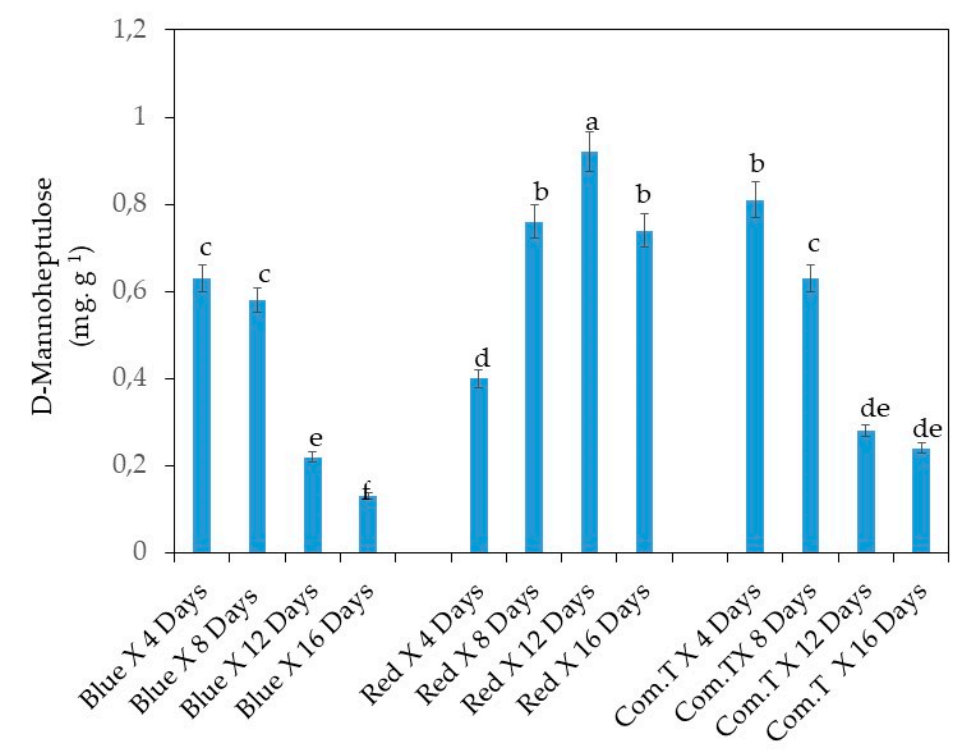

(A)

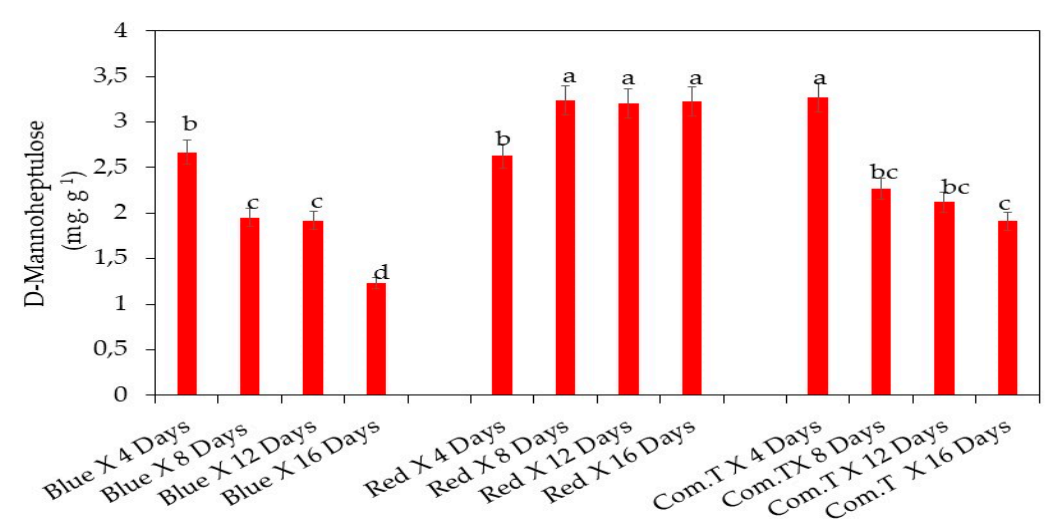

(B)

Figure 8. (A) Influence of LED lights on D-mannoheptulose and oleic acid content in the mesocarp of avocado cultivar Fuerte. (B) Influence of LED lights on D-mannoheptulose and oleic acid content in the mesocarp of avocado cultivar Hass. Mean \pm standard deviation values for each bar were calculated based on five fruits. Number of replicates per treatment $n=5$. Mean values of bars marked by different letters were significantly different at $p<0.05$, according to Fisher's protected LSD test. Blue, blue LED light; Red, red LED light; Com.T, commercial treatment.

\subsection{Effect of LED Light Treatments on Oleic Acid Content in the Mesocarp}

Oleic acid content was determined in ready-to-eat stage ripe fruit. Overall, all blue or red LED light treatments significantly increased the oleic acid (18:1) content in cv. Fuerte compared to the fruit treated with commercial fungicide, irrespective of the storage period. However, fruit exposed to red LED light and stored for 8 days showed lower concentrations than the fruit exposed to blue LED light and stored for similar storage periods (Figure 9A). A similar increased trend in accumulation of oleic acid (18:1) content in cv. Hass fruit exposed to blue LED or red LED light compared to the commercial fungicide treated fruit was observed, irrespective of the storage period (Figure 9B). 


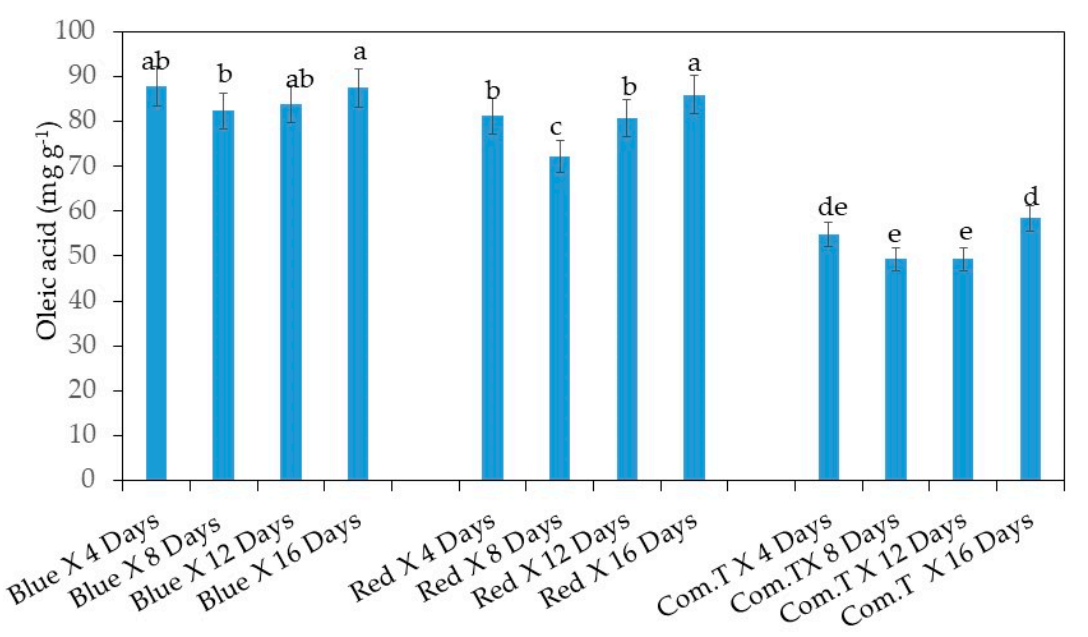

(A)

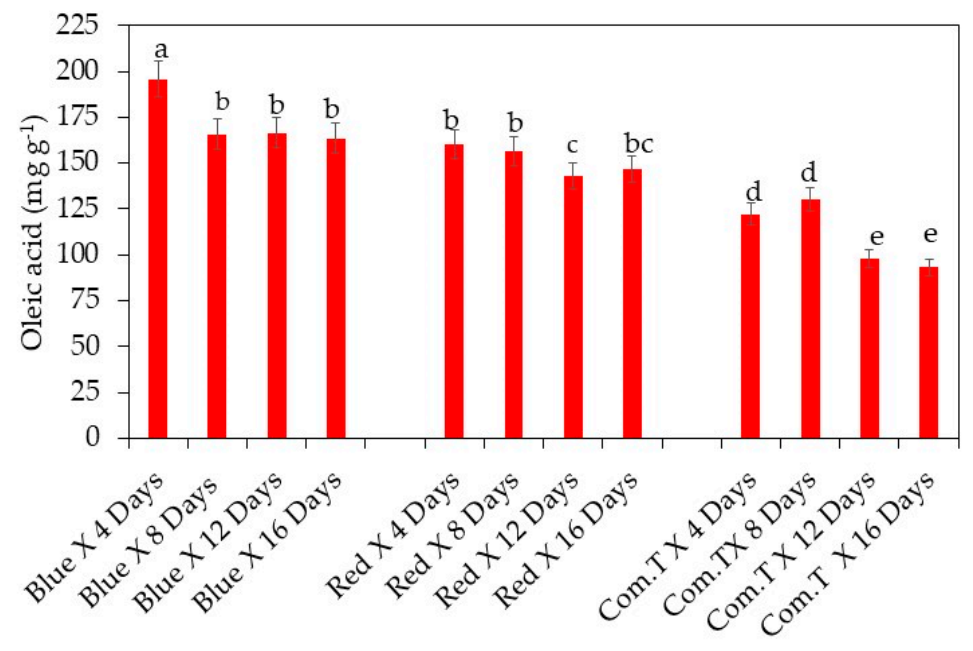

(B)

Figure 9. (A) Influence of LED lights on oleic acid content in the mesocarp of avocado cultivar Fuerte. (B) Influence of LED lights on oleic acid content in the mesocarp of avocado cultivars Hass and Fuerte. Mean \pm standard deviation values for each bar were calculated based on five fruits. Number of replicates per treatment $n=5$. Mean values of bars marked by different letters were significantly different at $p<0.05$, according to Fisher's protected LSD test. Blue, blue LED light; Red, red LED light; Com. T, commercial treatment.

\subsection{Effect of LED Light Treatments on Ascorbic Acid Content in the Mesocarp}

Overall, the ascorbic acid content was significantly lower in commercial fungicide treated cv. Fuerte fruit compared to the fruit exposed to blue LED light and stored for 6, 12, and 16 days or red LED light and stored for 4, 8, 12, and 16 days in storage (Figure 10A). Likewise, there were lower concentrations of ascorbic acid content detected in commercial fungicide treated fruit when compared to the blue or red LED light treated fruit stored for 4 to 16 days onwards. In other words, exposure to blue or red LED light improved the biosynthesis of ascorbic acid in cv. Hass (Figure 10B). 


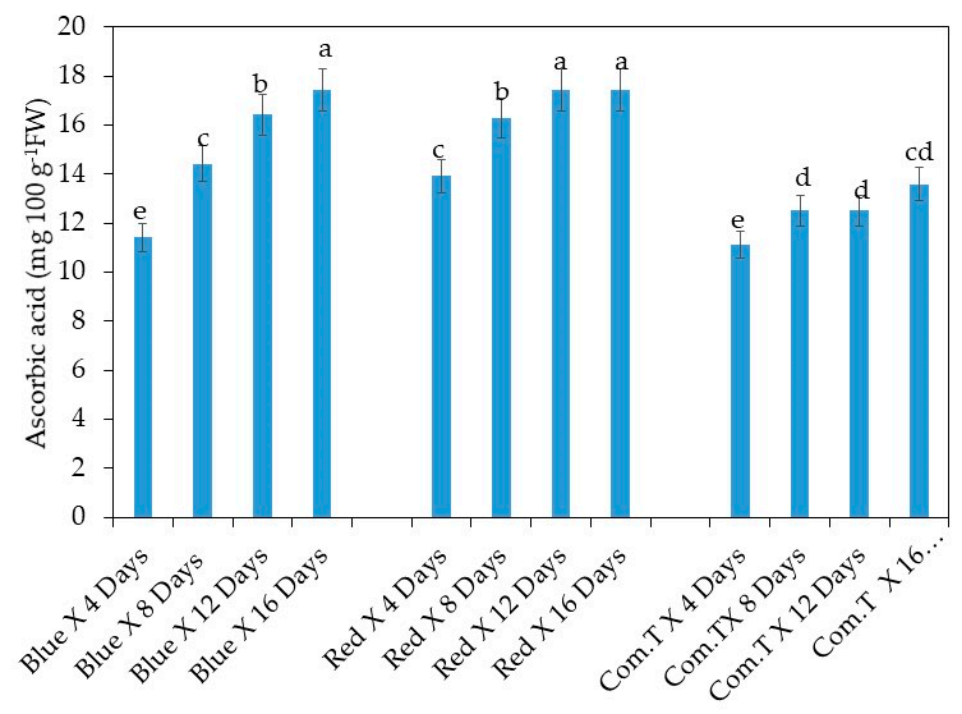

(A)

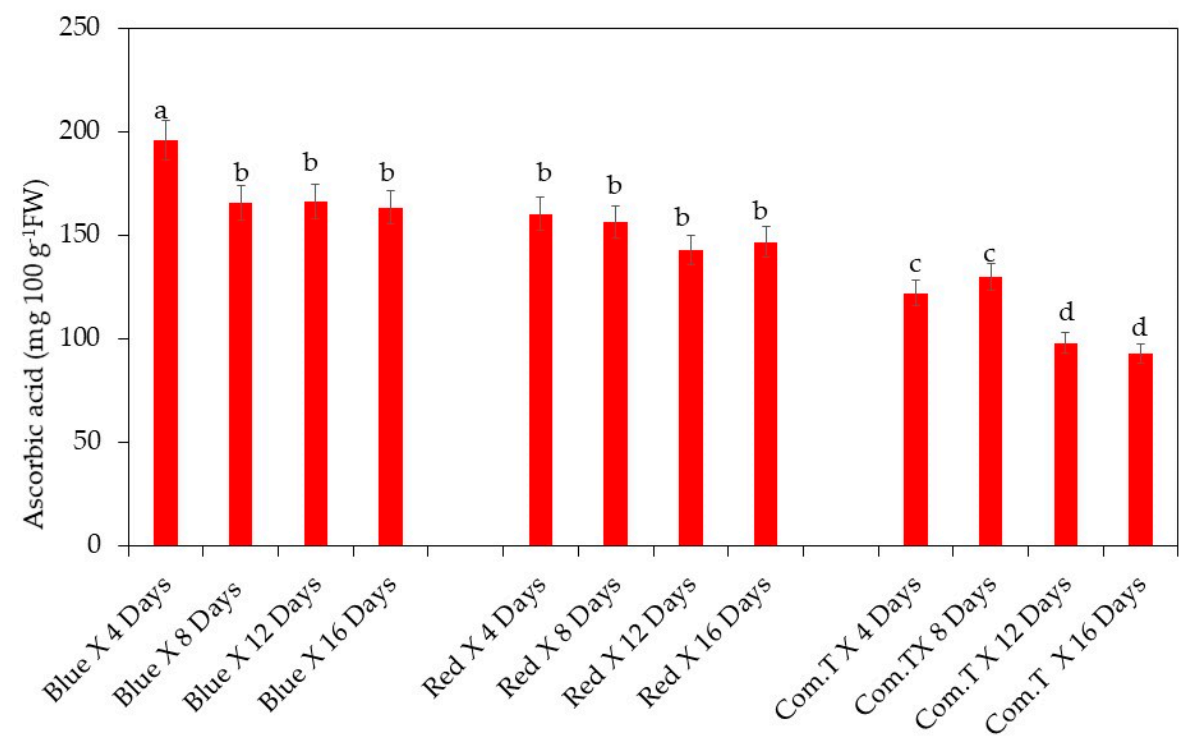

(B)

Figure 10. (A) Influence of LED lights on ascorbic acid content in the mesocarp of avocado cultivar Fuerte. (B) Influence of LED lights on ascorbic acid content in the mesocarp of avocado cultivar Hass. Mean \pm standard deviation values for each bar were calculated based on five fruits. Number of replicates per treatment $n=5$. Mean values of bars marked by different letters were significantly different at $p<0.05$, according to Fisher's protected LSD test. Blue, blue LED light; Red, red LED light; Com.T, commercial treatment.

\subsection{Effect of LED Light Treatments on Antioxidant Activity}

Antioxidant activity was significantly lowest in commercial fungicide treated cv. Fuertes from 4 days onwards up to 16 days compared to the fruit that underwent the other two postharvest treatments and was stored at similar storage periods. However, the significantly highest antioxidant activity was observed in fruit exposed to red LED light and stored for 12 days. In general, red LED light exposed fruit stored for 4 to 16 days and fruit exposed to blue LED light and stored for 12 days showed higher antioxidant activity (Figure 11A). 
Notably, cv. Hass had similar significantly increased antioxidant activity in fruit exposed to red LED light and stored from 4 days to 16 days compared to the fruits fruit from the other two postharvest treatments. Likewise, commercial fungicide treated cv. Hass showed significantly lowest antioxidant activity than the fruit from the other two postharvest treatments (Figure 11B). Ascorbic acid showed a strong positive correlation with antioxidant scavenging activity of cultivars Hass $(r=0.77, p<0.05)$ and Fuerte $(r=0.72, p<0.05)$.

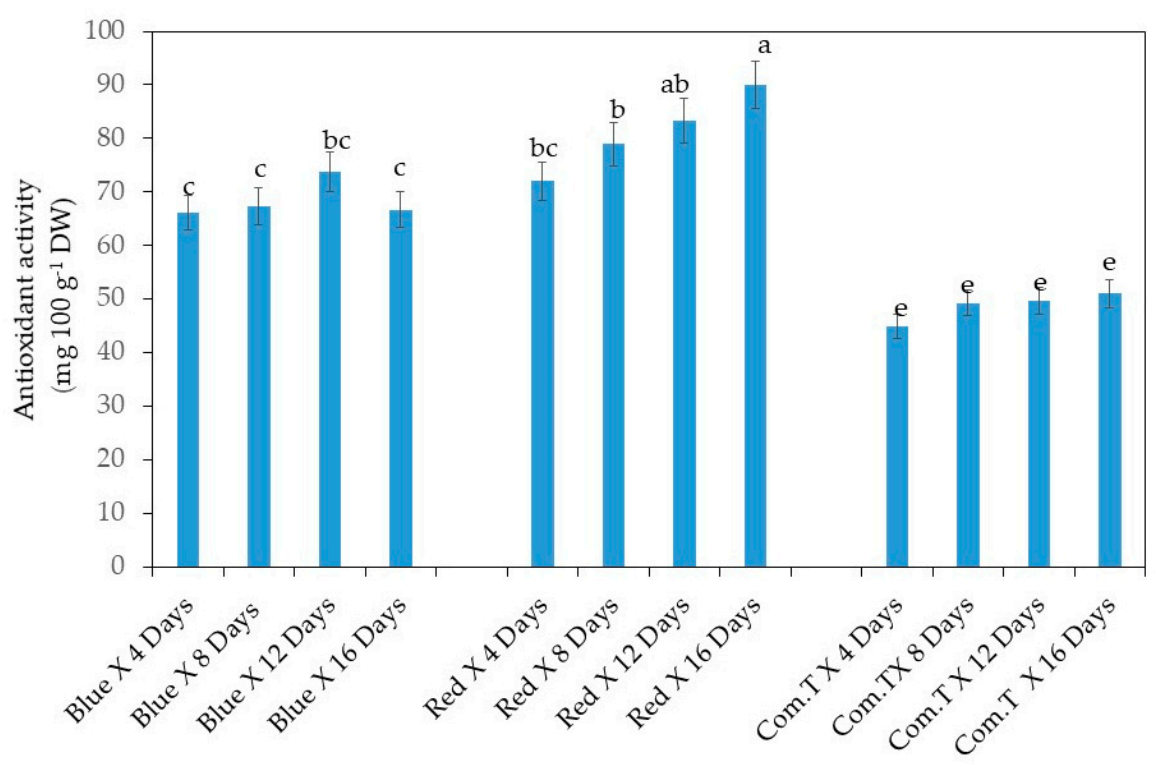

(A)

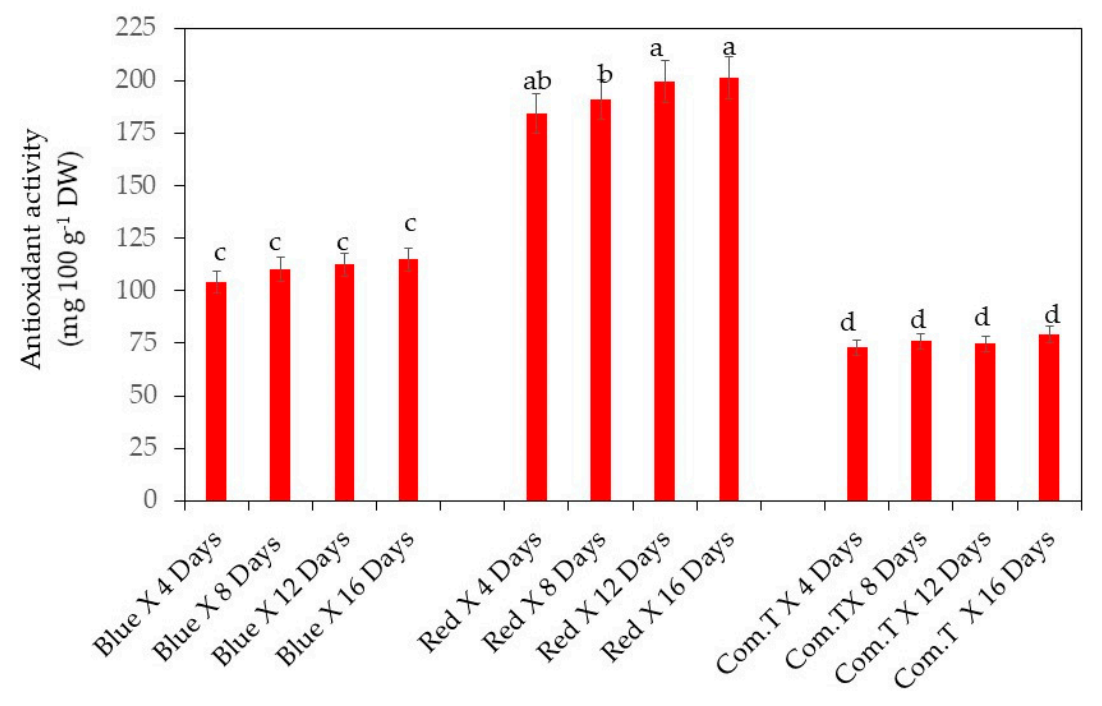

(B)

Figure 11. (A) Antioxidant metabolite contents in avocado cultivar Fuerte treated postharvest with LED lights. (B) Antioxidant metabolite contents in avocado cultivar Hass treated postharvest with LED lights. Mean \pm standard deviation values for each bar were calculated based on five fruits. Number of replicates per treatment $n=5$. Mean values of bars marked by different letters were significantly different at $p<0.05$, according to Fisher's protected LSD test. Blue, blue LED light; Red, red LED light; Com.T, commercial treatment. 
The performing of PCA analysis was to summarise the interrelated biochemical changes with different LED light treatments and storage periods for both avocado cultivars Hass and Fuerte. The obtaining of the two principal components with their factor loading was with respect to Eigen values $>1$. The principal components explained 71.4\% (PC1 38.2\% and 33.2\%) (Figure 12). In PC1, the components coefficients or correlation coefficients ( $r$ ) for the following parameters (variables): - oleic acid, ascorbic acid, and antioxidant activity, were positively loaded, and tryptophan was negatively loaded in PC1. In PC2: - 3-feruloyl quinic acid, coumaric acid hexoside, ready-to-eat ripeness were loaded positively and D- manoheptulose, firm fruit were loaded negatively. The PCA analysis confirmed the increase of 3-feruloyl quinic acid, coumaric acid hexoside in ready to ripe stage Hass and Fuerte avocado fruit exposed under blue LED light or treated with commercial fungicide and stored for 12 and 16 days. Both cultivars, stored for 8 and 12 days under red light, confirmed increased antioxidant activity, D- manoheptulose, tryptophan and skin epicatechin concentration and firm fruit.

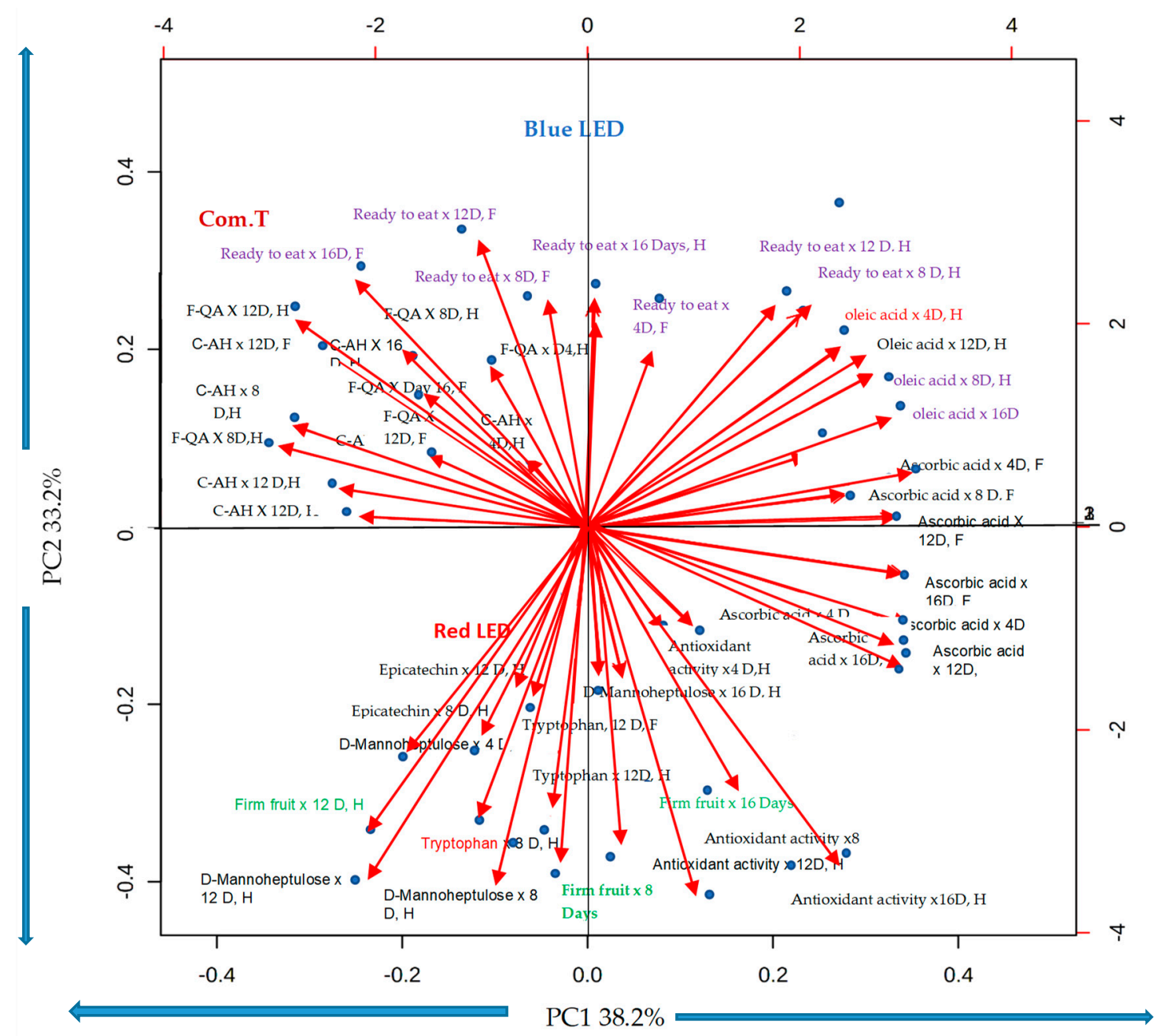

Figure 12. Principal component analysis (PCA) showing correlation loadings of fruit phenolic compounds; epicatechin in the pericarp; tryptophan, D-mannoheptulose sugar, ascorbic acid, oleic acid, and antioxidant activity in the mesocarp; and fruit ripeness related to the LED light treatments in comparison to the commercial treatment. F-QA, 3-feruloyl quinic acid; $\mathrm{C}-\mathrm{AH}$, coumaric acid hexoside; D, days; H, cv. Hass; F, Cv. Fuerte.

\section{Discussion}

In the fruit industry, there is a growing interest in protecting the fruit against postharvest decay using elicitors or resistance inducers to stimulate the natural compounds responsible for resistance against the postharvest pathogens, as this will promote sustainable plant protection against pathogens 
and reduce the loss of fruit during marketing. Use of LEDs is becoming a popular and handy tool for sustainable agricultural practices [20]. Antimicrobial properties of light are gaining more attention in fungi, as they are developing resistance against the conventionally used fungicides. Blue LEDs elicited resistance against green mould (Penicillium digitatum) decay in citrus (nonclimacteric fruit) by altering the phenolic profile, especially the scoparone content [21]. However, in our study, red LED light caused significant reduction in anthracnose incidence in both cultivars Fuerte and Hass, although the impact was higher in cv. Hass, primarily by eliciting resistance by upregulating the $P A L$ genes and increasing the epicatechin concentration (Figure 2A). A similar increase in PAL activity and PAL gene expression induced by postharvest treatments (e.g., thyme oil vapours) demonstrated the control of anthracnose decay in avocados [22]. Antifungal diene compound (AFD; 1-acetoxy-2-hydroxy-4-oxo-heneicosa-12, 15-diene) is responsible for the resistance of unripe avocado fruit against the anthracnose pathogen [23]. The AFD compound declines as the fruit ripens due to the activity of lipoxygenase enzyme and facilitates the entry of the pathogen into the fruit (host). Alternatively, emission of ethylene further facilitates the infection process of $C$. gloeosporioides. The concentration of epicatechin, a product of the phenylpropanoid pathway, regulates the activity of lipoxygenase and the levels of AFD compound [24-26]. Furthermore, upregulation of PAL gene expression was found to stimulate the biosynthesis of epicatechin content in the skin of avocado [22,23]. Results presented herein indicate that both cultivars (Fuerte and Hass) exposed to red LED for 12 day, via activation of the phenylpropanoid pathway, revealed PAL gene expression and epicatechin content in the skin (Figure $3 \mathrm{~A}, \mathrm{~B}$ and Figure $4 \mathrm{~A}, \mathrm{~B}$ ). This research reported this by demonstrating the low regulation of LOX genes in fruit exposed to LED light, the higher concentration of epicatechin in the fruit skin, and the observed reduction in anthracnose-infected fruits (Figure 2B).

Accumulation of tryptophan and the biosynthetic pathway guide the production of different secondary metabolites [27]. Fundamentally, tryptophan biosynthesis and the enzymes are induced by the stress reaction caused by biotic elicitors [27]. There is reportedly an interdependence of the shikimate pathway and the key phenylalanine-derived phenolics and phytoalexin via phenylalanine ammonia lyase in different fruits and vegetables [28,29]; similarly, red LED lights stimulated the accumulation of tryptophan amino acid in this study (Figure 6E,F). Sensitivity or response of the fruit or plant and the pathogen regarding the control of anthracnose during storage on the market shelf towards a specific monochromatic light is more likely due to the sensitivity of their light receptors than the energy or the wavelength of the specific light [30]. This could be the reason for the observed differences in response towards the different LED light treatments.

Blue LED light was found to accelerate the ripening in bananas (climacteric fruit), while red LED light delayed the ripening [31]. A similar trend was observed in both avocado cultivars (Fuerte and Hass) in this study (Figure 3); however, blue LED light showed a remarkable impact in ripening cvs. Fuerte and Hass on days 8 and 16 respectively. Huang et al. [31] investigated the impact of different LED lights and wavelengths on climacteric pattern and reported the blue light was the most effective in inducing the onset of the climacteric peak, but the red LED light slowed the ripening. The accelerated ripening in fruit exposed to blue LED light and reduction of epicatechin content in the avocado fruit skin could have aggravated the anthracnose of decay and the entry of $C$. gloesoporioides into the fruit (Figure 3A,B).

The C7 D-mannoheptulos correlated with time of ripening [16] and avocado (cv. Hass) grown under the red nets demonstrated higher concentration of D-mannoheptulos and the fruits took time to reach ready stage in our previous study [32]. Detected in all avocado cultivars, except cv. Bacon, during ripening were $p$-coumaric and ferulic acids (hydroxycinnamic acids) [33]. Fruit ripening of climacteric fruits such as tomato and kiwi showed an intense modification of nonvolatile secondary metabolites in the phenolic profile [34]. Some derivatives of phenolic compounds, such as coumaric and ferulic acid, reportedly increased linearly during development, and accumulation continued in the fully ripe fruit [34]. Likewise, our results showed an increase in coumaric acid hexoside and 3-feruloyl quinic acid related to the number of fruit reaching ready-to-eat stage ripeness exposed to blue LED 
light or commercial fungicide treatment (Figure 3A,B). Variability in avocado metabolites occurs due to different photoreceptors that sense each light, since the blue light is absorbed by the phototropin and cryptochrome and red light is absorbed by the phytochrome. Phytochromes mediate the red/FAR light related responses in plants and biosynthesis of phenolic compounds (phytochemicals). In our previous research, red net grown cv. Hass avocados showed higher PAL activity and accumulation of epicatechin and phenolic acid components [19]. The ascorbic acid content (vitamin C) was stimulated in cabbage stored under blue LED lights, which improved the ascorbic acid accumulation. However, based on the results presented here, in avocado cultivars Fuerte and Hass, the increase of ascorbic acid is favoured by the red LED light (Figure 10A,B). Furthermore, blue LED light was found to promote the synthesis of all free amino acids, except glutamic and aspartic acids, during postharvest ripening of tomatoes from green to yellow to red [11]. Likewise, in this study, blue and red LED light influenced the oleic acid biosynthesis in both avocado cultivars (Figure 9A,B). It is noteworthy that the production of antioxidants, ascorbic acid, and phenolic compounds and amino acid biosynthesis occur under more stressful conditions [35].

\section{Conclusions}

Application of the LED light technology to avocado at postharvest stage can be a useful tool to address the demand for fruits that have reached the ready-to-eat stage without compromising the fruit quality. Applying the blue LED light in cold storage can accelerate fruit ripening, whereas employing the red LED light can induce fruit resistance against the anthracnose postharvest disease in both avocado cvs. Fuerte and Hass for up to 12 days on the market shelf at $10-12{ }^{\circ} \mathrm{C}$. Further studies on the application of red and blue LED lights as a combined spectrum are imperative.

Author Contributions: S.M. performed the experiment, was responsible for the data collection, conducted formal analysis and the analysis of phenolic compounds, conducted statistical analysis, and wrote the first draft. D.S. conceptualised the research idea; supervised the first author; participated in discussion, review, editing, and data validation; was the grant holder and project administrator; provided resources; and revised the final draft. All authors have read and agreed to the published version of the manuscript.

Funding: This research was funded by National Research Foundation South Africa: [98352].

Acknowledgments: The financial support from the National Research Foundation, South Africa, and Grant number 98352 for Phytochemical Food Network to Improve Nutritional Quality for Consumers is greatly acknowledged.

Conflicts of Interest: Authors have no conflict of interest to declare.

\section{References}

1. Dreher, M.L.; Davenport, A.J. Hass avocado composition and potential health effects. Crit. Rev. Food Sci. Nutr. 2013, 53, 738-750. [CrossRef] [PubMed]

2. South African Avocado Grower's Association 2020. Available online: https://www.avocado.co.za/varieties/ (accessed on 15 May 2020).

3. Perkins, M.L.; Joyce, D.C.; Coates, L.M. Possible contribution of impact injury at harvest to anthracnose expression in ripening avocado: A review. Sci. Hortic. 2019, 246, 785-790. [CrossRef]

4. Daneel, M.S.; Sippel, A.; de Beer, M.; Mlimi, J. A look into the variability of prochloraz residues in the avocado industry. S. Afr. Avocado Growers Assoc. Yearbook 2016, 39, 92-98. Available online: http://www.avocadosource. com/Journals/SAAGA/SAAGA_2016/SAAGA_2016_39_PG_092.pdf (accessed on 14 October 2020).

5. Bill, M.; Sivakumar, D.; Beukes, M.; Korsten, L. Expression of pathogenesis-related (PR) genes in avocados fumigated with thyme oil vapours and control of anthracnose. Food Chem. 2016, 194, 938-943. [CrossRef] [PubMed]

6. Commission Regulation (EU) 2020/192. Amending Annexes II and III to Regulation (EC) No 396/2005 of the European Parliament and of the Council as Regards Maximum Residue Levels for Prochloraz in or on Certain Products. Available online: https://www.avocado.co.za/varieties/https://eur-lex.europa.eu/legalcontent/GA/TXT/?uri=CELEX:32020R0192 (accessed on 15 May 2020).

7. Munhuweyi, K.; Mpai, S.; Sivakumar, D. Extension of Avocado Fruit Postharvest Quality Using Non-Chemical Treatments. Agronomy 2020, 10, 212. [CrossRef] 
8. Bantis, F.; Smirnakou, S.; Ouzounis, T.; Koukounaras, A.; Ntagkas, N.; Radoglou, K. Current status and recent achievements in the field of horticulture with the use of light-emitting diodes (LEDs). Sci. Hortic. 2018, 235, 437-451. [CrossRef]

9. Taulavuori, E.; Taulavuori, K.; Holopainen, J.K.; Julkunen-Tiitto, R.; Acar, C.; Dincer, I. Targeted use of LEDs in improvement of production efficiency through phytochemical enrichment. J. Sci. Food Agric. 2017, 97, 5059-5064. [CrossRef]

10. Maroga, G.M.; Soundy, P.; Sivakumar, D. Different postharvest responses of fresh-cut sweet peppers related to quality and antioxidant and phenylalanine ammonia lyase activities during exposure to light-emitting diode treatments. Foods 2019, 8, 359. [CrossRef]

11. Dhakal, R.; Baek, K.H. Short period irradiation of single blue wavelength light extends the storage period of mature green tomatoes. Postharvest Biol. Technol. 2014, 90, 73-77. [CrossRef]

12. Yamaga, I.; Takahashi, T.; Ishii, K.; Kato, M.; Kobayashi, Y. Suppression of blue mold symptom development in satsuma mandarin fruits treated by low-intensity blue LED irradiation. Food Sci. Technol. Res. 2015, 21, 347-351. [CrossRef]

13. Obianom, C.P.; Romannazzi, G.; Sivakumar, D. Effects of chitosan treatment on avocado postharvest diseases and expression of phenylalanine ammonia-lyase, chitinase and lipoxygenase genes. Postharvest Biol. Technol. 2019, 147, 214-221. [CrossRef]

14. Fuchs, Y.; Zauberman, G. Physiological aspects of delayed marketing of avocado fruit. S. Afr. Avocado Growers Assoc. Yearbook 1987, 10, 132-135.

15. Glowacz, M.; Bill, M.; Tinyane, P.P.; Sivakumar, D. Maintaining postharvest quality of cold stored 'Hass' avocados by altering the fatty acids content and composition with the use of natural volatile compounds-methyl jasmonate and methyl salicylate. J. Sci. Food Agric. 2017, 97, 5186-5193. [CrossRef]

16. Mpai, S.; Sivakumar, D. Influence of growing seasons on metabolic composition, and fruit quality of avocado cultivars at 'ready-to-eat stage'. Sci. Hortic. 2020, 265, 109159. [CrossRef]

17. Meyer, M.D.; Terry, L.A. Fatty acid and sugar composition of avocado, cv. Hass, in response to treatment with an ethylene scavenger or 1-methylcyclopropene to extend storage life. Food Chem. 2010, 121, 1203-1210. [CrossRef]

18. Hoerwitz, W.; Latimer, G. International Official Methods of Analysis of the Association of Official Analytical Chemists (AOAC), 16th ed.; AOAC International: Rockville, MD, USA, 2000; Volume II.

19. Tinyane, P.P.; Soundy, P.; Sivakumar, D. Influence of photo-selective netting on fruit quality parameters and bioactive compounds in selected tomato cultivars. Sci. Hortic. 2013, 161, 340-349. [CrossRef]

20. Hasan, M.; Bashir, T.; Ghosh, R.; Lee, S.K.; Bae, H. An overview of LEDs' effects on the production of bioactive compounds and crop quality. Molecules 2017, 22, 1420. [CrossRef]

21. Ballester, A.R.; Lafuente, M.T. LED Blue Light-induced changes in phenolics and ethylene in citrus fruit: Implication in elicited resistance against Penicillium digitatum infection. Food Chem. 2017, 218, 575-583. [CrossRef]

22. Bill, M.; Korsten, L.; Remize, F.; Glowacz, M.; Sivakumar, D. Effect of thyme oil vapours exposure on phenylalanine ammonia-lyase (PAL) and lipoxygenase (LOX) genes expression, and control of anthracnose in 'Hass' and 'Ryan' avocado fruit. Sci. Hortic. 2017, 224, 232-237. [CrossRef]

23. Prusky, D.; Keen, N.T.; Eaks, I. Further evidence for the involvement of a preformed antifungal compound in the latency of Colletotrichum gloeosporioides on unripe avocado fruits. Physiol. Mol. Plant Pathol. 1983, 22, 189-195. [CrossRef]

24. Karni, L.; Prusky, D.; Kobiler, I.; Bar-Shira, E.; Kobiler, D. Involvement of epicatechin in the regulation of lipoxygenase activity during activation of quiescent Colletotrichum gloeosporioides infections of ripening avocado fruits. Physiol. Mol. Plant Path. 1989, 35, 367-374. [CrossRef]

25. Prusky, D. Pathogen quiescence in postharvest diseases. Annu. Rev. Phytopathol. 1996, 34, 413-434. [CrossRef] [PubMed]

26. Prusky, D.; Alkan, N.; Mengiste, T.; Fluhr, R. Quiescent and necrotrophic lifestyle choice during postharvest disease development. Annu. Rev. Phytopathol. 2013, 51, 155-176. [CrossRef]

27. Brader, G.; Tas, E.; Palva, E.T. Jasmonate-dependent induction of indole glucosinolates in arabidopsis by culture filtrates of the nonspecific pathogenerwinia carotovora. Plant Physiol. 2001, 126, 849-860. [CrossRef]

28. Dyer, W.E.; Henstrand, J.M.; Handa, A.K.; Herrmann, K.M. Wounding induces the first enzyme of the shikimate pathway in Solanaceae. Proc. Natl. Acad. Sci. USA 1989, 86, 7370-7373. [CrossRef] 
29. Henstrand, J.M.; McCue, K.F.; Brink, K.; Handa, A.K.; Herrmann, K.M.; Conn, E.E. Light and fungal elicitor induce 3-deoxy-D-arabino-heptulosonate 7-phosphate synthase mRNA in suspension cultured cells of parsley (Petroselinum crispum L.). Plant Physiol. 1992, 98, 761-763. [CrossRef]

30. Ensminger, P.A.; Schäfer, E. Blue and ultraviolet-B light photoreceptors in parsley cells. J. Photochem. Photobiol. A 1992, 55, 437-447. [CrossRef]

31. Huang, J.Y.; Xu, F.; Zhou, W. Effect of LED irradiation on the ripening and nutritional quality of postharvest banana fruit. J. Sci. Food Agric. 2018, 98, 5486-5493. [CrossRef]

32. Tinyane, P.P.; Soundy, P.; Sivakumar, D. Growing 'Hass' avocado fruit under different coloured shade netting improves the marketable yield and affects fruit ripening. Sci. Hortic. 2018, 230, 43-49. [CrossRef]

33. Hurtado-Fernández, E.; Pacchiarotta, T.; Romero, G.; Schoenmaker, B. Ultra-high performance liquid chromatography-time of flight mass spectrometry for analysis of avocado fruit metabolites: Method evaluation and applicability to the analysis of ripening degrees. J. Chromatogr. A 2011, 42, 7723-7738. [CrossRef] [PubMed]

34. Commisso, M.; Negri, S.; Bianconi, M.; Gambini, S.; Avesani, S.; Ceoldo, S.; Guzzo, F. Untargeted and targeted metabolomics and tryptophan decarboxylase in vivo characterization provide novel insight on the development of kiwifruits (Actinidia deliciosa). Int. J. Mol. Sci. 2019, 20, 897. [CrossRef] [PubMed]

35. Zhou, S.H.; Zhong, X.F.; Yuan, L.; Jian, C.C.; Dong-hong, L.; Xing-qian, Y. Phenolics and antioxidant properties of bayberry (Myrica rubra Sieb. et Zucc.) pomace. Food Chem. 2009, 112, 394-399. [CrossRef]

Publisher's Note: MDPI stays neutral with regard to jurisdictional claims in published maps and institutional affiliations. 